\title{
Long-term potentiation and long-term depression: a clinical perspective
}

\author{
Timothy V.P. Bliss,' Sam F. Cooke" \\ 'National Institute for Medical Research, Ridgeway, Mill Hill, London, U.K. "Picower Institute for Learning and Memory, Massachusetts Institute of \\ Technology, Cambridge, Massachusetts, U.S.
}

Long-term potentiation and long-term depression are enduring changes in synaptic strength, induced by specific patterns of synaptic activity, that have received much attention as cellular models of information storage in the central nervous system. Work in a number of brain regions, from the spinal cord to the cerebral cortex, and in many animal species, ranging from invertebrates to humans, has demonstrated a reliable capacity for chemical synapses to undergo lasting changes in efficacy in response to a variety of induction protocols. In addition to their physiological relevance, long-term potentiation and depression may have important clinical applications. A growing insight into the molecular mechanisms underlying these processes, and technological advances in non-invasive manipulation of brain activity, now puts us at the threshold of harnessing long-term potentiation and depression and other forms of synaptic, cellular and circuit plasticity to manipulate synaptic strength in the human nervous system. Drugs may be used to erase or treat pathological synaptic states and non-invasive stimulation devices may be used to artificially induce synaptic plasticity to ameliorate conditions arising from disrupted synaptic drive. These approaches hold promise for the treatment of a variety of neurological conditions, including neuropathic pain, epilepsy, depression, amblyopia, tinnitus and stroke.

KEYWORDS: LTP; LTD; synaptic plasticity; STDP; TMS; IPAS; TENS; DCS; VNS.

Bliss TVP, Cooke SF. Long-term potentiation and long-term depression: a clinical perspective. Clinics. 2011;66(S1):3-17.

Received for publication on March 31, 2011; Accepted for publication on April 1, 2011

E-mail: tbliss@nimr.mrc.ac.uk

\section{INTRODUCTION}

Long-term potentiation (LTP) is a form of activitydependent plasticity which results in a persistent enhancement of synaptic transmission. LTP has been a source of great fascination to neuroscientists since its discovery in the early 1970's ${ }^{1}$ because it satisfies criteria proposed by Donald Hebb for a synaptic memory mechanism in his influential book 'The Organization of Behavior'. ${ }^{2}$ Notably, LTP is longlasting and input-specific (changes can be induced at one set of synapses on a cell without affecting other synapses). The complementary process of long-term depression (LTD), in which the efficacy of synaptic transmission is reduced, shares these characteristics and has also received much attention as a candidate mnemonic process. ${ }^{3,4}$ Whether LTP and LTD are the actual synaptic processes underlying learning and memory, as most neuroscientists believe, has not yet been definitively resolved. ${ }^{5,6}$ However, at the molecular level, it is very clear that LTP/LTD and many forms of memory rely upon similar molecular mechanisms. In addition, it has been demonstrated that LTP- and LTDlike changes in synaptic strength occur as a memory is formed at various sets of synapses in the brain, and that these changes can occlude the artificial induction of LTP and can be occluded by the prior induction of LTP. ${ }^{7-13}$ The

Copyright (c) 2011 CLINICS - This is an Open Access article distributed under the terms of the Creative Commons Attribution Non-Commercial License (http:// creativecommons.org/licenses/by-nc/3.0/) which permits unrestricted noncommercial use, distribution, and reproduction in any medium, provided the original work is properly cited. debate on the relevance of LTP and LTD to human memory will in all likelihood continue until we can harness these processes to mimic the formation of a memory without prior experience. $^{14}$

LTP and LTD have another potentially important role in modern neuroscience, and that is the possibility that they may be exploited to treat disorder and disease in the human central nervous system (CNS). A variety of neurological conditions arise from lost or excessive synaptic drive due to sensory deprivation during childhood, brain damage or disease. Manipulation of synaptic strength using various developing technologies may provide a means of normalizing synaptic strength and thereby ameliorating plasticityrelated disorders of the CNS. In this review we will discuss clinical applications of LTP, LTD and related forms of synaptic plasticity and the technologies that may allow the erasure and induction of changes in synaptic strength in the human CNS. As a framework for this discussion we will first provide some background on LTP and LTD.

\section{Features of LTP/LTD: animal studies}

LTP was originally observed in vivo in the hippocampus of anaesthetized rabbits at synapses between the medial perforant path and granule cells of the dentate gyrus. ${ }^{1}$ In this study, LTP was induced using a stimulating electrode to induce a brief high-frequency train of action potentials in the afferent pathway, thereby ensuring coincident pre- and post-synaptic depolarization. Recordings of the synaptic response (the population EPSP) evoked in the population of activated granule cells revealed a lasting enhancement of synaptic strength following tetanic (high frequency) 
stimulation. Subsequent studies have been almost exclusively conducted on rats and mice. Later it was found that low frequency trains of electrical stimulation $(1 \mathrm{~Hz})$ can induce LTD in hippocampal and cortical pathways. ${ }^{15,16}$ Experiments in intact animals allow for assessment of the longevity of LTP in the hippocampus using chronically implanted recording and stimulating electrodes. ${ }^{17}$ Under these conditions, and using multiple induction tetani, LTP has been observed to last for a year in rats. ${ }^{18}$ In vitro preparations, however, have provided most of the insights relating to the cellular mechanisms of synaptic plasticity. LTP and LTD have been studied throughout the CNS but, most commonly, at Schaffer collateral-pyramidal cell synapses in the CA1 region of the rodent transverse hippocampal slice. ${ }^{19}$ This preparation has proved advantageous in several ways, not least because it allows for patchclamp recordings to be conducted with relative ease, thereby enabling experimental control over membrane potential. This approach has revealed that repeated pairing of single presynaptic stimuli (causing transmitter release) with post-synaptic depolarization is sufficient to induce LTP, bypassing the requirement for high frequency stimulation. ${ }^{20}$ Furthermore, the concept of spike timing-dependent plasticity (STDP) has been developed following the important observation in other in vitro preparations that the timing of pre- and post-synaptic action potentials (spikes) determines the polarity of synaptic change. Repeated activation of a presynaptic spike followed by post-synaptic spike, within a brief time window of approximately $50 \mathrm{~ms}$, leads to LTP, while the reverse order leads to LTD. ${ }^{21,22}$ The transverse slice allows for easy placement of stimulating electrodes in clearly defined afferent fibre populations because the dendritic and cell body subfields can be visualized. Independent stimulation of two afferent pathways has revealed that neighbouring synapses can be independently potentiated or depressed. This property of 'input specificity' is an important characteristic of Hebbian LTP and $\operatorname{LTD}^{4,23}$ (see figure 1). The same two-pathway approach led to the discovery of another key characteristic of LTP, associativity. LTP is associative because weakly stimulated synapses, which would not ordinarily undergo potentiation because insufficient postsynaptic depolarization is achieved, do so when the weak stimulation is paired with strong, LTP-inducing, stimulation of other synapses on the same cell. ${ }^{24}$ As initially implied by $\mathrm{Hebb}^{2}$ associativity of synaptic storage mechanisms might reflect the associative nature of human memory. These three characteristics of longevity, input-specificity and associativity are important, not just because they fulfill criteria predicted of an efficient memory mechanism, but because they provide clues as to the molecular mechanisms underlying LTP and LTD, mechanisms that could potentially be addressed to rectify synaptic malfunction.

\section{Molecular mechanisms of induction}

The transverse slice has the further advantage of allowing the rapid application and removal of pharmacological agents in order to examine their impact on the various phases of LTP and LTD. In this way, the involvement of a wide range of receptors, enzymes and other intracellular signaling molecules in the induction, expression and maintenance of LTP and LTD has been tested. This approach, combined with genetic manipulations in mice to remove or express key proteins, has permitted an extensive characterization of the molecular underpinnings of synaptic plasticity. That LTP requires near simultaneous pre- and post-synaptic depolarization indicates the involvement of a coincidence detection mechanism. It is now known that coincidence detection is accomplished through the NMDA receptor (NMDAR), a voltage-dependent subtype of glutamate receptor that allows permeation of calcium and other cations only when two criteria are satisfied: neurotransmitter is bound following release of glutamate from the presynaptic terminal, and the post-synaptic membrane is sufficiently depolarized to allow the ejection of $\mathrm{Mg} 2+$ ions which, at near-resting membrane potentials, block the ion pore of NMDARs. ${ }^{25}$ Blockade of NMDAR with selective antagonists, such as AP5, CPP or MK801, prevent the induction of LTP but has no effect on its maintenance. ${ }^{26}$ Genetic manipulation to prevent NMDAR expression in the CA1 pyramidal cell population also prevents the induction of LTP, as well as the expression of several forms of hippocampus-dependent memory. ${ }^{27}$ Interestingly, this antagonism also blocks the induction of hippocampal LTD, ${ }^{4,28}$ demonstrating that the two forms of plasticity share a common NMDAR-dependent induction mechanism. Calcium influx through the NMDAR is central to the induction of both LTP and LTD because intracellular application of calcium chelators, such as BAPTA or EGTA, prevents induction of plasticity. ${ }^{28,29}$ Moreover, uncaging of calcium itself can induce a form of LTP or LTD, ${ }^{30}$ depending on the concentration of calcium, and both effects are occluded by electrically induced plasticity. ${ }^{31}$ These are the canonical induction mechanisms for hippocampal LTP/LTD but it is clear that there exist at these synapses and throughout the CNS a wide range of other forms of LTP/LTD that do not rely upon the NMDAR, notably LTD that is induced through activation of the metabotropic glutamate receptor (mGluR). ${ }^{32,33}$ In addition, the induction protocols that lead to LTP or LTD can vary in different parts of the CNS; for instance, pairing of pre- and post-synaptic depolarization that would lead to LTP in the hippocampus results in LTD at parallel fibre-Purkinje cell synapses in the cerebellar cortex. Purkinje cells are GABAergic and therefore have an inhibitory action on their targets; thus, LTD in this case has a similar net effect to LTP at excitatory principal cells. ${ }^{3}$

\section{Expression}

A wide range of calcium-detection mechanisms has been implicated in the interface between LTP/LTD induction and expression. Activation of enzymes, such as cyclic AMP (cAMP)-dependent kinase (PKA) and calcium calmodulindependent kinase 2 (CaMKII), is essential for induction of the canonical NMDAR-dependent form of LTP in area CA1 of the hippocampus. Both kinases detect elevations in the level of calcium, either directly or indirectly, and are known to phosphorylate proteins that are involved in the expression of LTP, notably AMPA receptors (AMPAR), ${ }^{34}$ altering their function in ways that enhance synaptic efficacy - for example, by increasing channel conductance. ${ }^{35}$ Conversely, phosphatases such as calcineurin and PP1, which are also sensitive to calcium but at lower concentrations, can dephosphorylate the same or different protein residues either to reverse LTP, through a process of depotentiation, or to induce de novo LTD, by reducing AMPAR efficacy. ${ }^{36}$ Thus a complex interplay between the activity of kinases and phosphatases, enzymes which can also either directly or indirectly cross-modulate each others' activity, determines the polarity of synaptic plasticity. ${ }^{37}$ Persistent activation of 
A

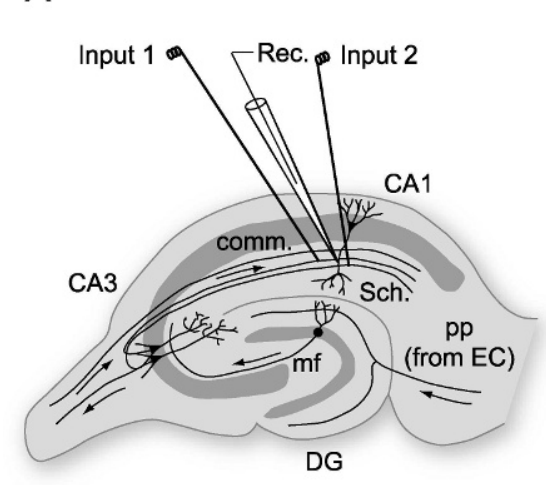

B

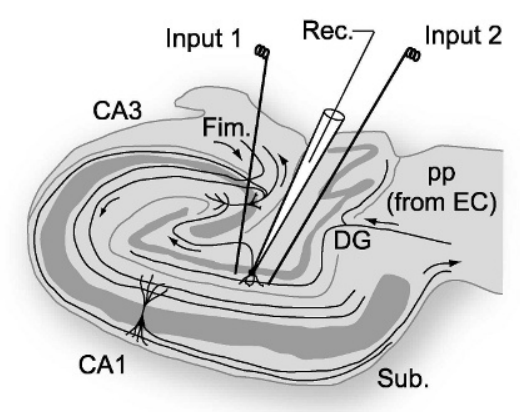

C

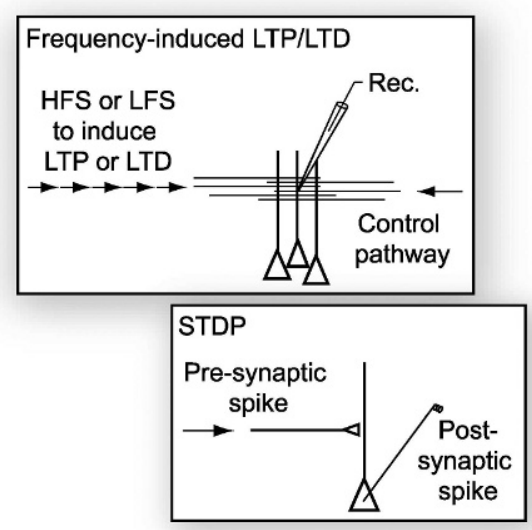

D

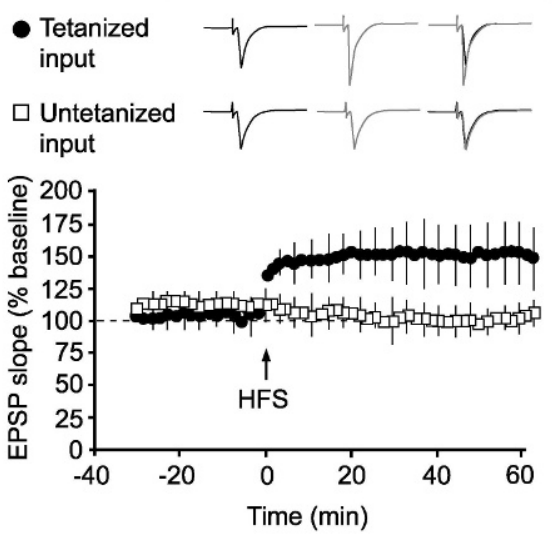

E
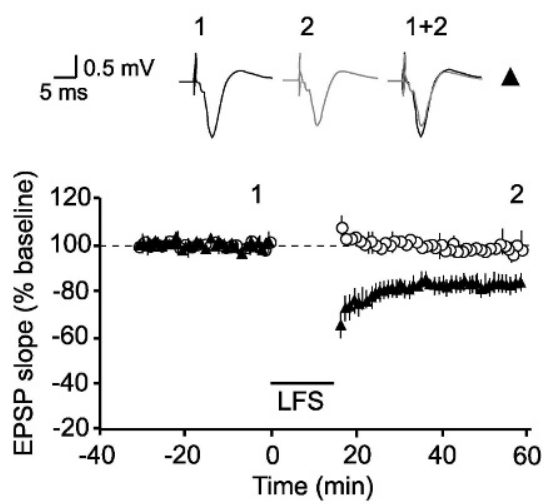

$\mathrm{F}$

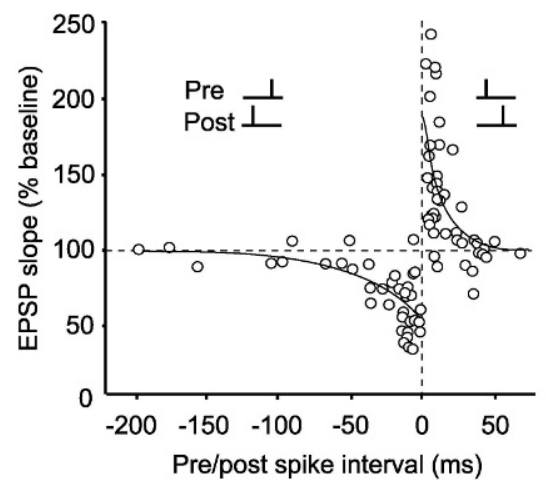

Figure 1 - LTP and LTD: Induction protocols (A) Schematic of the rodent transverse hippocampal slice, the mostly commonly used preparation for studying LTP, LTD and related phenomena. In the configuration shown, an extracellular recording electrode is placed among apical dendrites of CA1 pyramidal cells, and stimulating electrodes are positioned in the Schaffer (Sch) collaterals to stimulate two separate input pathways. (B) A transverse view of the human hippocampus showing electrode placements for stimulating and recording in the dentate gyrus. ${ }^{67}$ (C) Diagram showing how LTP and LTD are induced in a pathway (input 1) by high-or low-frequency stimulation (HFS or LFS) respectively, while a second pathway acts as a control (see D,E). A related form of plasticity, known as spike timing-dependent plasticity (STDP), can be induced by repeated pairing of presynaptic and postsynaptic firing. Depending on the relative timing, LTP or LTD is induced (see F). (D) LTP in a two-pathway experiment in the dentate gyrus of human hippocampus. Normalized values of the slope of the population EPSP are plotted for potentiated and control pathways. After a baseline period of test stimulation at $1 \mathrm{stim} / \mathrm{min}$, a brief burst of high-frequency stimulation (HFS, $100 \mathrm{~Hz}$ for $1 \mathrm{sec}$, arrow) is delivered. The potentiation of the response to resumed test stimulation is present immediately after HFS, and persists for at least one hour (black circles) while the control pathway (open squares) remains unaffected, demonstrating the input-specificity of LTP. ${ }^{67}$ Sample field potentials are shown pre- and post-tetanus. (E) LTD in area CA1 of rat hippocampal slices induced by low frequency stimulation (LFS, $\sim 1 \mathrm{~Hz}$ ) for around 15 minutes (bar). This form of plasticity is also input-specific; only the pathway subjected to LFS is depressed (black circles) (adapted from ${ }^{4}$ ). (F) The polarity of synaptic plasticity induced by STDP protocols is determined by the relative timing of pre- and post-synaptic spiking. If an action potential is repeatedly evoked before pre-synaptic stimulation then, provided the interval is brief enough, a depression of synaptic strength ensues. If the order is reversed so that pre-synaptic activation precedes the post-synaptic spike, as would happen if the synaptic input contributed to triggering an action potential, then LTP is induced (rat hippocampus, adapted from ${ }^{22}$ ).

these mechanisms initiates a cascade of signaling events that culminate in gene expression and the production of new proteins, ${ }^{38}$ eventually resulting in much more robust, longlasting changes in synaptic strength. These protein synthesis-dependent mechanisms underlie the sustained expression of LTP/LTD beyond the first few hours, when the early phase of plasticity (E-LTP and E-LTD) gives way to the late phase (L-LTP and L-LTD). Much of the signaling from the synapse to the nucleus that initiates novel gene transcription is accomplished by a cAMP-dependent signaling cascade involving PKA, mitogen activated protein kinases (MAPK) and the transcription factor cAMP-responsive element binding protein (CREB). ${ }^{39,40}$ Modulatory neurotransmitters such as dopamine (DA), noradrenaline (NA), serotonin (5$\mathrm{HT}$ ) and acetylcholine (ACh), which act on their respective receptors to activate cAMP-dependent signaling in neurons, ${ }^{41-44}$ also play a role in regulating the longevity of synaptic plasticity. Broadly speaking these neurotransmitters serve as physiological effectors of reward, punishment, arousal and attention, all brain-states that modulate the longevity of memory. Once transcription has occurred the relevant plasticity-related proteins are incorporated, by a process that is not well understood, into just the synapses that are undergoing change and not their neighbours. An interesting theory of synaptic tagging, ${ }^{45}$ which now has considerable experimental backing, ${ }^{46,47}$ proposes that a molecular tag is placed at synapses undergoing inputspecific plasticity. Newly translated effector proteins are globally expressed and the molecular tag ensures that the relevant effectors are captured only by recently active synapses expressing the tag. The seeming metabolic profligacy of this system may be partially overcome by 
local translation of existing or newly transcribed mRNAs at ribosomes positioned in the dendrites; local protein synthesis, triggered by a molecular tag, would drastically reduce the number of protein molecules required to potentiate or depress individual synapses. ${ }^{48,49}$ The molecules that act as tags are not yet determined but there have been some interesting recent proposals, and there is also now a better understanding of what the effector proteins themselves are, as we now discuss.

\section{Maintenance}

CaMKII has also been championed as a long-term maintenance mechanism for $\mathrm{LTP}^{37}$ because it can phosphorylate itself and in this way remain autonomously active for a period of time after the dissipation of elevated calcium. This attribute, in principle, would allow it to act as a 'memorase' ${ }^{50}$ Whether or not CaMKII does actually maintain LTP expression for long periods of time has been questioned. ${ }^{51}$ Inhibitors of this kinase appear to have little effect on already established LTP. ${ }^{52}$ However, recent data suggests that it may remain active for several minutes after LTP induction. This could enable the kinase to act as a 'tag' for recently potentiated synapses and allow for the synapse-specific recruitment of newly synthesized proteins that participate in the maintenance of longlasting synaptic potentiation. ${ }^{46}$ Another kinase, PKM $\zeta$, has now been recognized to act in a localized fashion to maintain synaptic potentiation for long periods of time. This kinase, an atypical isoform of the calcium-dependent kinase PKC, is remarkable in that it is newly expressed after LTP induction and remains persistently active, in part because it lacks a regulatory domain that would put a brake on its activity in the absence of calcium. Thus, the kinase is capable of maintaining LTP expression at least for its own lifetime and, probably through persistent expression and some as yet not fully understood autoregulation, for much longer periods. ${ }^{53}$ Indeed, L-LTP can be reversed at least a day after induction through specific inhibition of this kinase in vivo. ${ }^{54}$ It is now known that PKM $\zeta$ maintains LTP by increasing the number of AMPARs in the synapse, thereby keeping synaptic transmission potentiated. $^{55}$ There is abundant evidence that expression of LTP depends on persistent increases in AMPAR number in the synapse, ${ }^{56}$ although pre-synaptic changes in the probability of neurotransmitter release also play a role, and in some circumstances a dominant role, in supporting at least the early phase of LTP. ${ }^{57-59}$ The evidence for presynaptic involvement in the expression of LTP in the hippocampus is strong, and has been hard to reconcile with the compelling evidence for changes in glutamate receptor number and/or modification; we are still some way from a unified model of LTP expression. ${ }^{60}$ LTD also relies on both pre and post-synaptic expression mechanisms ${ }^{61}$ although here too the maintenance mechanism is not fully understood.

Finally, it is important to mention that structural changes in the size and shape of pre- and post-synaptic specializations may mediate permanent or near-permanent changes in synaptic efficacy. Growth may allow for an increase in the size or number of active zones on both sides of the synapse. Spines can increase in volume after L-LTP induction and decrease after L-LTD induction. ${ }^{62}$ The degree to which structural re-organisation of synapses occurs in adult animals is not yet clear. An intriguing participant in this later phase of synaptic plasticity is brain-derived neurotrophic factor (BDNF), a substance that is newly synthesised as a result of MAPK and CREB signaling and which may initiate structural change at tagged synapses. ${ }^{63}$ The role of BDNF in synaptic plasticity is multimodal and it participates in the early phases of both LTP and LTD through corelease with presynaptic glutamate. BDNF, initially in the form pro-BDNF, binds to two postsynaptic receptors: the tyrosine kinase B (TrkB) receptor, whose activation facilitates the induction of LTP, ${ }^{64}$ and the P75 receptor, whose activation results in an alteration of the subunit composition of the NMDA receptor that promotes the subsequent induction of LTD. ${ }^{65}$ Thus, BDNF is a major player in synaptic plasticity, although its action is complex (see figure 2).

\section{LTP and LTD in human hippocampal slices}

Many of the mechanisms described above have since been demonstrated to be crucial for LTP in hippocampal tissue excised from humans undergoing temporal lobe surgery to alleviate otherwise intractable epilepsy. In these slice studies, LTP was readily induced in the temporal lobe and at perforant path-granule cell synapses in the dentate gyrus (see figure 1B) using induction tetani comparable to those used in slices from mouse brain. ${ }^{66,67}$ LTP in human tissue could be blocked by application of the NMDAR antagonist AP5, just as in animal models. Furthermore, artificial elevation of cAMP through application of forskolin, which increases adenylate cyclase activity, results in chemicallyinduced LTP, a phenomenon that is well documented in rodent hippocampal slices $^{68}$ and a principal piece of evidence for the involvement of the cAMP-dependent cascade in L-LTP. These studies are important for their verification that the human brain supports an LTP-like phenomenon, but it should be borne in mind that the tissue may have been in a pathological state as it was taken from individuals with an epileptic focus in the temporal lobe. Indeed, slices taken from individuals in whom the focus was present in the hippocampus itself produced far less LTP than those in whom the focus was elsewhere in the temporal lobe. It is possible that LTP was occluded in those slices taken directly from the vicinity of an epileptic focus by previous synaptic potentiation occurring through excessive neural activity. In keeping with this notion, levels of CaMKII expression were found to be significantly higher and levels of the phosphatase PP2B significantly lower in dentate granule cells of individuals with hippocampal epileptic foci. ${ }^{69}$ Thus, unsurprisingly, it is clear that LTP can be readily induced in the human CNS and that several molecular mechanisms are shared with rodent models. With this in mind we can now consider whether LTP and LTD can be harnessed for therapeutic purposes in humans (see Table 1).

\section{Inducing LTP and LTD-like changes in the human CNS non-invasively}

Broadly speaking there are two categories of non-invasive approach that can be taken to induce lasting change in neural activity in the human CNS. The first category mimics the high- or low-frequency electrical stimulation used to induce LTP or LTD, respectively. The second removes the requirement for frequency-based stimulation and instead attempts to mimic pairing or STDP-like protocols of induction (see figure $1 \mathrm{~F}$ and figure 3 ). 


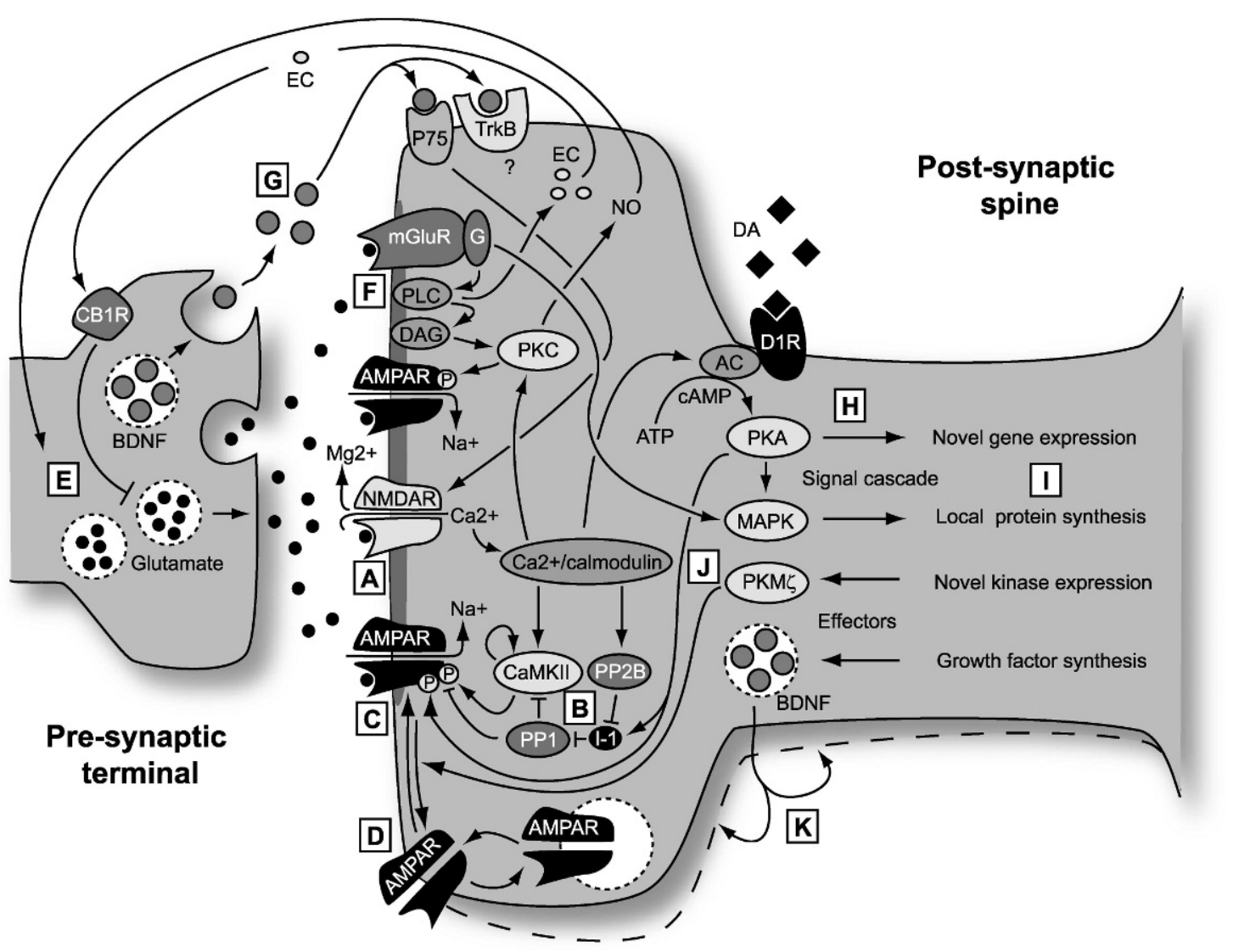

Figure 2 - LTP and LTD: Schematic of molecular mechanisms. (A) The induction of canonical forms of both LTP and LTD is triggered by activation of the NMDA class of glutamate receptor. This ionotropic receptor detects the coincidence of presynaptic and strong postsynaptic activity by a mechanism that involves both the binding of transmitter and depolarization-induced repulsion of the Mg ${ }^{2+}$ ions that block its ionophore at near-resting membrane potentials. In its unblocked state $\mathrm{Ca}^{2+}$ ions are able to permeate the channel, gaining access to $\mathrm{Ca}^{2+}$-dependent processes in the spine and triggering synaptic plasticity. (B) $\mathrm{Ca}^{2+}$ binds to $\mathrm{Ca}^{2+} / \mathrm{calmodulin}^{2}$ which, in turn activates numerous kinases and phosphatases, including CaMKII, PKC and Calcineurin (PP2B) directly and PKA and PP1 indirectly. The balance of kinase and phosphatase activity depends on the concentration and temporal profile of the postsynaptic Ca ${ }^{2+}$ transient (including $\mathrm{Ca}^{2+}$ released from intracellular stores). The $\mathrm{Ca}^{2+}$ transient determines the polarity of the induced plasticity, with low and prolonged $\mathrm{Ca}^{2+}$ transients inducing LTD and brief, steeper transients inducing LTP. (C) One means by which LTP is expressed is through phosphorylation of the AMPA receptor, an ionotropic glutamate receptor that mediates baseline chemical transmission at excitatory synapses in the CNS. Phosphorylation by CaMKII enhances the conductance of these channels. LTD, by contrast, results, in part, from the dephosphorylation of the AMPA receptor by phosphatases. (D) Trafficking of AMPA receptors plays a major role in the expression of LTP and LTD by increasing or decreasing the number of receptors in the postsynaptic membrane. (E) Presynaptic mechanisms leading to a sustained increase in the probability of transmitter release also contribute to the expression of LTP. The relative contributions of preand post-synaptic mechanisms may vary at different times after induction and also across different classes of synapse. Since induction of LTP and LTD is controlled by the post-synaptic NMDA receptor, any presynapic component of expression requires a retrograde messenger that can signal to the pre-synaptic terminal that coincidence has occurred. Two candidates are nitric oxide (NO) and endocannabinoids (EC). (F) A second form of LTD that has been much studied is dependent on group 1 metabotropic glutamate receptors (mGluR). Glutamate binding to this receptor initiates a signal cascade, involving the breakdown of the membrane lipid PIP 2 by phospholipase $\mathrm{C}\left(\mathrm{PLC}\right.$ ) to the important signaling molecules $\mathrm{IP}_{3}$, which releases $\mathrm{Ca}^{2+}$ from $\mathrm{Ca}^{2+}$ stores (not shown) and diacylglycerol (DAG), which leads to the activation of the calcium sensitive kinase PKC. This enzyme then phosphorylates the AMPA receptor but in such a manner that the conductance is reduced. An offshoot is the production of NO. (G) Brain-derived neurotrophic factor (BDNF) plays a complicated role in both LTP and LTD and contributes in different ways to short-term and long-term plasticity. (H) Longerlasting 'late' forms of LTP and LTD, persisting for more than a few hours, require the synthesis of new proteins, either through novel gene transcription or through initiation of local translation of existing transcripts. Novel gene expression requires signaling to the nucleus from newly potentiated or depressed synapses. A major player in this process is the cAMP-dependent signaling cascade initiated by calcium influx and involving adenylyl cyclase (AC) and CAMP-dependent kinase (PKA), which also acts directly on the AMPA receptor in LTP expression. Catecholaminergic modulatory input plays a major role in determining the longevity of LTP and LTD, through interaction with AC which increases levels of CAMP and thereby activates PKA. PKA then sets in action a chain of signals that leads to the expression of new transcripts which, in turn are translated into proteins contributing to the long-term expression of synaptic plasticity. This signaling pathway has been a major recent target of attempts to find nootropic substances. (I) There are parallel signaling pathways, involving mitogen activated protein kinases (MAPK), that also result in the synthesis of new proteins. However, in this case existing transcripts are locally translated into proteins, without further requirement for nuclear signaling. The MAPK pathway is strongly implicated in mGluR-dependent LTD. (J) One newly synthesized protein that acts as a maintenance mechanism for late LTP is PKM $\zeta$. This remarkable kinase comprises the active subunit of PKM, an isoform of PKC, that is now known to maintain the presence of AMPA receptors inserted during LTP induction, and thereby maintain LTP. Inhibition of this kinase can erase LTP and memory many days after induction. (K) Finally, BDNF can also play a second role in synaptic plasticity, as a newly synthesized product that alters the structure of the synapse to enforce long-term changes in synaptic strength. 


\section{Repetitive Transcranial Magnetic Stimulation (rTMS)}

rTMS delivers relatively small electrical currents generated by fluctuating magnetic fields administered over the skull using a figure-of-eight magnetic coil. In most cases it only allows for the excitation of neural circuitry in structures relatively close to the brain surface. For this reason the technique has primarily been used in the neocortex and is not a suitable substitute for the kind of invasive deep brain stimulation (DBS) currently used to treat Parkinson's disease. ${ }^{70}$ Single TMS pulses evoke eventrelated potentials (ERPs) that can be recorded using scalp recording electrodes. Importantly, delivery of a high frequency train of rTMS pulses can induce lasting potentiation of ERP amplitude and low frequency rTMS can have the opposite effect. In primary sensory cortex, ERPs can be generated by discrete, transient sensory stimuli within the modality of interest. These ERPs also undergo amplitude potentiation as a result of tetanic stimulation with rTMS. ${ }^{71}$

rTMS is being assessed as a potential treatment for a number of neurological disorders. Parkinson's disease is a common neurodegenerative disorder that results from the specific loss of dopaminergic cells in the substantia nigra (s.n.) leading to tremor, and impairment of movement initiation and termination. Deep brain stimulation of subthalamic nuclei is a well established treatment in advanced cases of Parkinson's disease, and can be very effective. ${ }^{72}$ rTMS has been suggested as an alternative, noninvasive treatment. Although the primary locus of dysfunction in Parkinson's is too deep for standard rTMS there are secondary effects that can be addressed with rTMS. When cells in the s.n. degenerate, a conspicuous beta-frequency synchronized activity arises in primary motor cortex (M1) that is believed to contribute to limb rigidity and akinesia. ${ }^{73}$ In an established animal model of Parkinson's disease, in which primates are treated with MPTP, a substance which selectively kills dopaminergic cells in the s.n., this synchronization of activity in M1 occurs in addition to all the classic motor symptoms of Parkinson's disease. Delivery of high-frequency rTMS $(130 \mathrm{~Hz})$ to M1 in these monkeys induces a lasting amelioration of rigidity and akinesia. ${ }^{74}$ Promisingly, rTMS has also been applied to motor cortex in human Parkinson's sufferers to produce significant but short-lasting improvements in motor performance. ${ }^{75}$ This example illustrates the important point that, even if the primary area of dysfunction in the CNS is not accessible to non-invasive stimulation, secondary dysfunction in more superficial regions can be targeted in order to ameliorate the resulting behavioral abnormality. ${ }^{76}$ It is worth noting, though, that a very recently developed technology, 'deep' rTMS $^{77}$ may soon permit non-invasive stimulation of deep targets such as the thalamus, basal ganglia and brainstem nuclei without delivering dangerously large currents to the overlying cortex. This technique, which uses a threedimensional magnetic coil system that surrounds the cranium in order to generate activity at much greater depths than the traditional figure-of- 8 system, may come to replace DBS as a non-invasive treatment for Parkinson's disease. It may also be of benefit in the treatment of obesity, Alzheimer's disease and depression.

A long standing treatment for major depression has been electroconvulsive therapy (ECT). Although still one of few effective treatments for this troubling disorder, it is only used when antidepressants fail because it requires anaesthesia and carries the risk of neural damage. One effect of ECT may be to reduce cortical excitability and, thereby, reverse increases in the excitability of cerebral cortex, notably within prefrontal cortex, during treatment-resistant depression. ${ }^{78}$ Two explanations have been offered for pathological increases in excitability - a persistent decrease in inhibitory tone, or a persistent potentiation of excitatory synapses as a result of an LTP-like process. ECT results in the expression of several biochemical markers of LTD in animals $^{79}$ suggesting that ECT causes induction of de novo LTD - or depotentiation of already potentiated synapses - in the cortex. Low frequency rTMS, thought to induce LTDlike plasticity in humans, has been applied to the prefrontal cortex to achieve results similar to ECT in depressive patients. ${ }^{80}$ rTMS may, therefore, eventually serve as a more controlled and focused alternative to ECT, one which does not require anaesthesia and can be used over multiple sessions without fear of major brain damage.

The fact that low frequency rTMS can be used to reduce cortical excitability, perhaps through LTD-like plasticity in humans ${ }^{71,81}$ suggests that it may also be a potential treatment for epilepsy. Epilepsy results from hyperexcitability, perhaps through excessive LTP at glutamatergic synapses, or through other mechanisms such as increased intrinsic excitability or reduced inhibition. Thus, LTD-like plasticity, induced with low frequency rTMS, may provide a means to reverse LTP at saturated synapses in order to reduce circuit excitability. Low frequency $(0.3 \mathrm{~Hz})$ rTMS was first used as a treatment for epilepsy in an open-case study performed over a decade ago, resulting in a significant reduction in the incidence of seizures for up to a month after five days of treatment. ${ }^{82}$ Subsequent doubleblind randomized trials have produced mixed results, ${ }^{83,84}$ and it is clear that further work is required to identify more precisely the type of epilepsies that respond to rTMS and to optimize the parameters of stimulation in different cases. Generalized seizures may be more responsive than focal seizures, particularly where the focus is in deep brain structures.

The potential of rTMS to address epileptic foci has brought to the fore the importance of navigation. The efficacy of rTMS can be greatly increased if it is coupled with imaging techniques such as functional MRI (fMRI) to map the affected area, or by systematically recording the effects of stimulation on ERP amplitude or motor output. ${ }^{85}$ This approach enables the tailoring of treatment to individual cases. For disorders such as Parkinson's disease it is very clear which structure in the brain is the primary site of pathology and, although there are slight individual differences in brain shape, it is relatively straightforward to target the region to be stimulated with DBS. In the case of stroke, a condition in which rTMS application to primary motor cortex holds promise as a treatment, the region of major dysfunction must be tracked in the individual before TMS is applied because each stroke victim has a unique pattern of damage. Neuro-navigated TMS maps motor evoked potentials (MEPs) and the motor threshold for eliciting responses from the muscles of interest to optimise TMS delivery points in individual subjects. ${ }^{86,87}$ High frequency rTMS can then be used to enhance motor output in affected regions. A systematic study of the efficacy of neuro-navigated TMS as compared to conventional stereotaxically-guided TMS, targeting the representation of the dorsal interosseous muscle of the hand and evaluating the 
impact of rTMS on reaction time and pinch force, revealed significantly greater efficacy for navigated TMS in both these behavioral outputs as well as in potentiating MEPs and reducing motor threshold. ${ }^{88}$

In summary, rTMS holds promise in the treatment of a variety of neurological disorders, perhaps through the induction of LTP and LTD-like plasticity. Advances in technology, allowing reliable, safe stimulation of deep structures and careful individual tailoring of stimulation sites and protocols using neuro-navigated TMS, will only expand this potential (Figure 3A).

\section{Transcutaneous electrical nerve stimulation (TENS)}

Electrical stimulation can also be delivered directly to peripheral nerves through the skin to induce LTP-like and LTD-like changes in central neural responsiveness. Certain clinical conditions result from pathology just a single synapse from the periphery and may be addressed with TENS. Chief amongst these conditions is hyperalgesia. Plasticity at two locations contributes to this chronic pain condition which arises from repeated peripheral application of a noxious stimulus to the periphery. The first occurs at the point of nociception itself (peripheral sensitization); and the second at the first central synapses in the pathway within the dorsal horn of the spinal cord (central sensitization). ${ }^{89}$ High frequency electrical stimulation can be delivered to nociceptive $C$ fibres in animal preparations ${ }^{90,91}$ to induce a lasting form of LTP within the dorsal horn. Alternatively, LTP can be induced at these same synapses through natural stimulation of peripheral nociceptors with heat, the noxious chemical formalin or mechanical pinching of the skin. ${ }^{92}$ Some of this potentiation is homosynaptic and confined to the stimulated nociceptive (C) fibres but there is also a component of heterosynaptic potentiation that enhances transmission at other, surrounding $C$ fibres, and may contribute to secondary hyperalgesia. In addition, sensory (A) fibres that do not mediate nociception may also be potentiated heterosynaptically by $\mathrm{C}$ fibre stimulation, perhaps through changes in the intrinsic excitability of common target cells in the dorsal horn. As a result there can be a lasting sensitization of sensory nerves around the site of injury leading to hypersensitivity to non-noxious stimuli (allodynia). ${ }^{89}$

Central sensitization has several molecular parallels with LTP in the hippocampus. ${ }^{93}$ LTP in the $C$ fibre pathway is both NMDAR-dependent and calcium-dependent, ${ }^{94,95}$ and also relies upon other molecular players such as Substance P and the NK-1 receptor. ${ }^{96}$ Blockade of the NMDA receptor with the non-competitive antagonist ketamine during surgery in humans helps to prevent central sensitization and reduce subsequent hyperalgesia on recovery, ${ }^{97}$ and other NMDA receptor antagonists have similar effects, ${ }^{98}$ Given the evidence for the involvement of LTP in hyperalgesia, as well as other forms of peripheral and central plasticity that increase responsiveness to peripheral stimulation, one clinical approach is to attempt to reverse central sensitization in the dorsal horn with low frequency stimulation of C fibres to induce LTD, or to ameliorate peripheral sensitization by reducing dorsal horn responsiveness with LTD of all afferent sensory fibres. TENS delivered to peripheral nerves containing both $\mathrm{A}$ and $\mathrm{C}$ fibres can be used to induce LTP or LTD in the dorsal horn. Significantly, these forms of plasticity respectively increase or decrease the perception of pain in human subjects, ${ }^{99,100}$ so that, for example, pinpricks become less painful after the delivery of low frequency TENS. The effect of inducing LTD is, however, complicated by the fact that, while low frequency stimulation reduces pain sensitivity directly at the conditioning site, it has the reverse effect of secondary hyperalgesia at adjacent sites. ${ }^{99}$ It is also important to note that low frequency stimulation of $C$ fibres, which mimics a characteristic activity pattern after injury, can induce LTP with similar biochemical hallmarks to that induced with high frequency stimulation. ${ }^{96}$ In fact, the most effective way to induce LTD of C fibre-evoked responses in the dorsal horn is to stimulate at a low intensity that will activate A fibres specifically and not the $C$ fibres themselves. ${ }^{91}$ Thus, it is clear that while the use of TENS holds promise for addressing hyperalgesia, the condition is complex and is likely to require additional treatments to ameliorate all its various components. Nonetheless, we regard the use of TENS to treat neuropathic pain as an exemplar for the development of non-invasive clinical strategies based on the induction or suppression of LTP or LTD. The fact that peripheral stimulation can be delivered immediately afferent to the targeted synapses, as well as the availability of good animal models of hyperalgesia, emphasises the potential for a non-invasive strategy based on TENS. Rational drug design based on manipulating the potentiated and/or depressed state of synapses at the first stages of transmission in peripheral nociceptive pathways offers another promising approach.

The application of TENS has largely been limited to situations where stimulation of monosynaptic pathways is possible. Potentiation or depression may occur di or trisynaptically but this is difficult to monitor, or to predict, as the frequency of stimulation will change due to filtering by afferent circuitry. Nevertheless, it is known that hyperalgesia is associated with changes in the brain as well as those documented in the spinal cord. The cortex, notably somatosensory cortex and anterior cingulate cortex (ACC), has been a site of investigation because peripheral injury, in the form of removal of a digit in rats, induces NMDARdependent plasticity in these regions of cortex. ${ }^{101,102}$ There are at least three synapses between nociceptive inputs and cortical synapses undergoing LTP-like plasticity but it may be that chronic pain arises from a concatenation of pathological synaptic plasticity at multiple synapses throughout the CNS. Indeed, the delivery of high frequency TENS, producing hypersensitivity to tactile stimulation, does lead to a potentiation of ERPs in the cortex ${ }^{100}$ and delivery of low frequency stimulation with rTMS in the cortex can lead to a temporary relief of chronic pain. ${ }^{103}$ In a fascinating recent study of hyperalgesia induced by peripheral nerve injury in mice, local inhibition in the ACC of $\mathrm{PKM} \zeta$ a key maintenance molecule for NMDAR-dependent LTP, resulted in reversal both of LTP-like plasticity induced in the ACC by nerve damage and reduction of hypersensitivity to tactile stimuli. ${ }^{104}$ This latter study opens up another intriguing avenue of treatment for neurological disorders arising from pathological LTP-like plasticity, namely the local and selective erasure of potentiation by suppressing the activity of PKM $\zeta$. From a clinical perspective the major problem with this approach is the fact that it would be highly invasive if used in humans and potentially dangerous given the indiscriminate nature of the PKM $\zeta$ inhibitor in erasing synaptic plasticity and memory. However, there may be other means of selectively erasing LTP such 


\section{Frequency-induced LTP/LTD-like plasticity:}
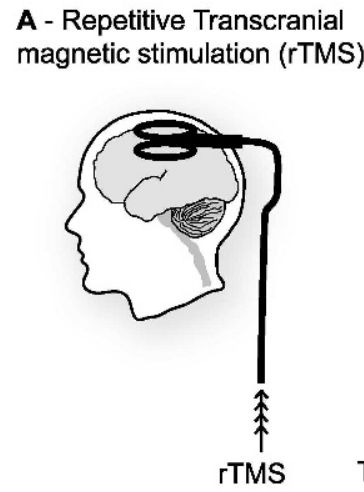

B - Transdural electrical nerve stimulation (TENS)

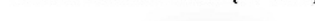

\section{C - Sensory Tetanus}

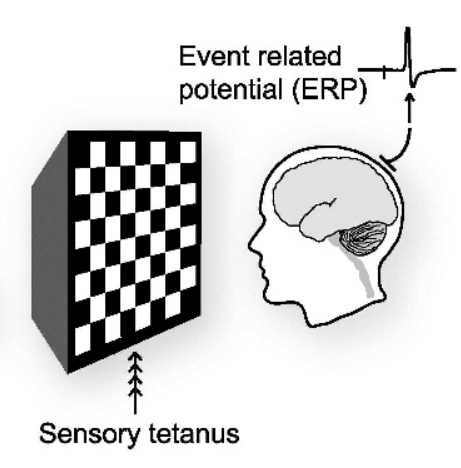

\section{Combinatorial Approaches:}

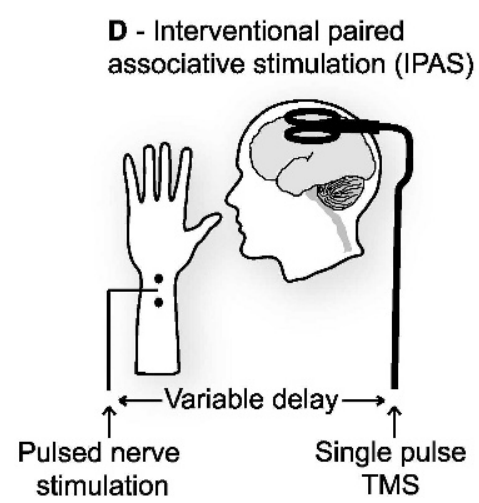

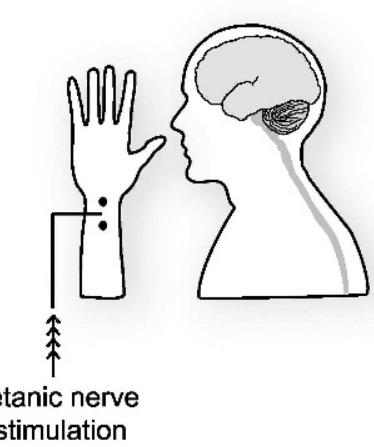

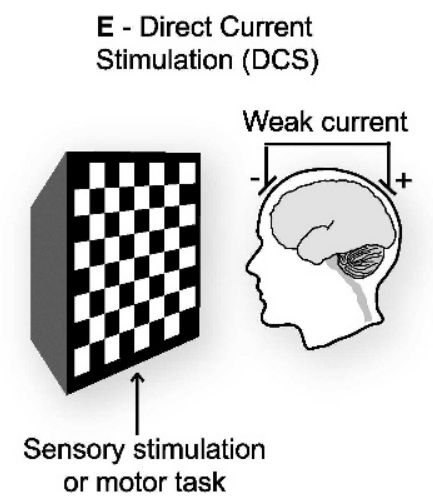

\begin{abstract}
F - Pharmaceutical modulation
\end{abstract}

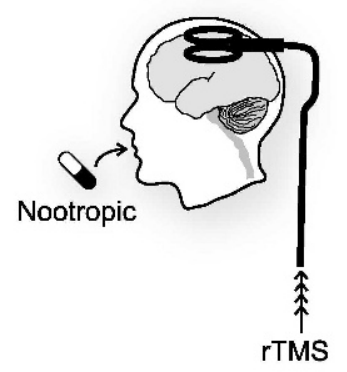

Figure 3 - Non-invasive methods of inducing synaptic plasticity in the human CNS. (A) Repetitive trains of transcranial magnetic stimulation (rTMS), have been employed in several regions of the brain to induce LTP- and LTD-like changes in spontaneous neural activity and responsiveness to stimulation. This approach is limited in the frequencies that can be attained and is restricted to surface structures in the brain, primarily cortical, close enough to the TMS device for effective stimulation. (B) Direct transdural electrical nerve stimulation (TENS) can be used to deliver trains of stimuli to afferent fibres and induce LTP- or LTD-like changes within the spinal cord. (C) Work in primary sensory cortices, notably visual and auditory cortex, has revealed that repetitive sensory stimulation, either flashes or tones, can induce lasting LTP- or LTD-like changes in event-related potentials (ERPs) recorded in these regions. (D) Approaches which combine two of the techniques described above (A-C) can be used to induce changes in synaptic strength that often have the added advantage of reducing the amount of stimulation required and restricting the focus of the effect. Interventional paired associative stimulation (IPAS) mimics STDP protocols by combining rTMS with TENS, or sensory stimulation, to induce lasting changes in neural responsiveness. Just as in STDP, the timing of the two stimuli, in this case one peripheral and one central, determines the polarity of change. (E) As well as TMS, direct current stimulation (DCS) can be used to depolarize neurons in the cortex non-invasively. This technique delivers a very weak current continuously over an extended period. There is some indication that DC stimulation in itself can result in lasting changes in neural responsiveness. However, there is substantial evidence that when be combined with tetanic stimulation, or a sensori-motor task, long-lasting changes in synaptic strength can be induced. (F) Another less temporally defined means of modulating the effects of any direct stimulation of the brain is through the ingestion or injection of drugs. Thus far there has not been a great deal of work on combining nootropics with sensory or direct brain stimulation but this is surely an avenue that is ripe for exploration.

as depotentiation, ${ }^{36,105,106}$ a phenomenon related to but mechanistically different from LTD. For a limited time after induction, LTP can be reversed, or depotentiated, by lowfrequency stimulation, suggesting a potential role for TENS or rTMS in the treatment of pathological plasticity, particularly in cases where the patient can be brought to treatment soon after the causative event.

\section{Photic and auditory tetanization}

A series of animal and human studies has demonstrated that plasticity can be induced in primary sensory cortices without electrical stimulation. Here, the electrical stimulus is replaced by rapid sensory stimulation within the modality of interest. ${ }^{107}$ For example, LTP-like changes, as measured using changes in the amplitude of one component of the visual evoked potential (VEP), can be induced in visual cortex using a photic tetanus $(9-13 \mathrm{~Hz})$ that consists of flashing or phase-reversing visual stimuli (for example, checkerboards or sinusoidal gratings) on a computer monitor. ${ }^{108-110}$ Three important criteria must be met if the location of plasticity underlying this phenomenon is to be securely identified. First, potentiation should be specific to the particular stimulus, so that the potentiation is no longer expressed if the spatial frequency ${ }^{109}$ or the orientation ${ }^{108}$ of the stimulus is altered, consistent with plasticity occurring in primary visual cortex, where representations of sensory primitives such as orientation and spatial frequency have not yet been integrated into more complex object representations. ${ }^{111}$ This latter observation is reminiscent of the well-documented phenomenon of perceptual learning, in which over time subjects become gradually more and more proficient at responding to 
highly specific visual stimuli, ${ }^{112}$ and is also consistent with observations made in animals using photic stimulation, in which potentiation of VEPs is both eye-specific and orientation-specific. ${ }^{113}$ Second, in these animal models it is possible to intervene in the visual pathway and substitute electrical thalamic stimulation for baseline photic stimulation and observe potentiation of the electrically evoked test responses after inducing potentiation using photic stimulation. ${ }^{13,114}$ The converse is also observed. LTP induced in primary visual cortex of the rat using tetanic electrical stimulation of the thalamus is also reflected in a potentiation of the VEP. ${ }^{13,115}$ Therefore, the plasticity underlying VEP potentiation does not occur in the retina or in retinothalamic pathways, but in the thalamocortical projection. Finally, it is worth noting that induction of similar plasticity can be prevented through local blockade in visual cortex of AMPA receptor insertion ${ }^{113}$ or systemic blockade of NMDA receptors, ${ }^{113,114}$ and expression of LTP can be reversed with local inhibition of $\mathrm{PKM} \zeta^{13}$ in rodents. Thus, mechanisms that support LTP also support potentiation of VEPs with photic stimulation.

From a clinical perspective, this work may prove useful in treating monocular amblyopia, a prevalent disorder that affects around $1 \%$ of individuals worldwide. Amblyopia results from a mismatch in ocular function early in life, leading to preferential allocation of visual cortex to input through the fully functional eye. Many of the ocular dysfunctions that cause this disorder, such as cataracts (lens opacity), anisometropia (mismatched lens refraction) and strabismus (misalignment of the eyes) can be fully repaired. However, if treatment is delayed beyond around 8 years of age in humans, as often occurs for either diagnostic or economic reasons, the cortex will not recover normal responsiveness to input through the previously dysfunctional eye. ${ }^{116}$ Extensive work in animals has demonstrated that monocular deprivation through eyelid suture, which models the causes of amblyopia in humans, results in LTD of excitatory transmission within visual cortex. ${ }^{117-119}$ Therefore, an obvious strategy to rescue the effects of amblyopia is to artificially induce LTP at the same synapses. Two treatments that have been shown to have some efficacy in adult amblyopes are perceptual learning ${ }^{120,121}$ and rTMS, ${ }^{122}$ although in general functional recovery has been both modest and short-lived. Future studies may make use of high frequency photic stimulation as a means of recovering function through the amblyopic eye (Figure $3 \mathrm{C}$ ). It is also worth considering combinatorial approaches to inducing LTP; peripheral sensory stimulation, combined with central activation by rTMS, may be more fruitful in inducing lasting plasticity.

\section{Interventional Paired-Associative Stimulation (IPAS)}

One non-invasive way to achieve an effect akin to spike timing-dependent plasticity (STDP) in the human cortex would be to activate afferent sensory pathways using, for example TENS or visual stimulation, in appropriately timed conjunction with single pulses of TMS to activate postsynaptic neurons at the target site. This approach, known as interventional paired associative stimulation (IPAS), uses the amplitude of the event-related potential (ERP) to determine the point at which peripheral stimulation initiates synaptic release. Central stimulation can then be delivered either before or after this delay in order to induce LTD or LTP-like effects, respectively (Figure 3D). Note that while
IPAS, like STDP, depends on the relative timing of pre- and post-synaptic events, the parallel is not exact, since in the case of IPAS polysynaptic pathways are involved. One clear advantage of IPAS over frequency-based methods is that it avoids potential risks associated with the delivery of highfrequency stimulation - there are reported instances of seizure as a result of using high-frequency rTMS. ${ }^{123}$

IPAS has been applied in both somatosensory cortex and motor cortex, using ERPs in response to stimulation of the median and ulnar nerves as a metric of plasticity in the cortex. Responses of the abductor pollicis brevis (APB) and abductor digiti minimi (ADM) muscles in the hand, to both peripheral stimulation and single cortical TMS pulses, also served as an assay of enhanced or decreased functional output. ${ }^{124}$ One beautiful aspect of the results from these experiments is the regional specificity of the LTP/LTD-like effects. Appropriate timing of nerve stimulation with somatosensory cortical stimulation can lead to a specific enhancement of ERPs driven in a small partial handrepresentation area in cortex without effect on neighbouring representations, ${ }^{125}$ which contrasts with a broader effect of direct rTMS application. This specificity also holds true for motor output as the muscle response to probe stimulation, either peripherally or cortically, can be potentiated or depressed by appropriate IPAS delays without effect on the neighbouring control muscle. ${ }^{126}$ The immediate import of this work, from a clinical perspective, may be in addressing focal dystonia, such as writer's cramp, in which chronic spasm or cramping develops in hand muscles, preventing the performance of fine motor skills such as writing. It is unclear whether this disorder arises primarily from cortical or basal ganglia dysfunction but the responses in sufferers of writer's cramp to IPAS were markedly different from normal control subjects in that the specificity of the effect was lost. In contrast to the effects in control subjects, targeting one muscle with IPAS had a comparable potentiating or depressing effect on the other, control muscle, which had not undergone IPAS. ${ }^{127}$ Thus, a loss of specificity in cortical connectivity may contribute to the dystonia. This example provides an illustration of how non-invasive stimulation techniques in humans may provide information about the aetiology of disorders - almost as important an outcome as the development of a treatment itself.

\section{Direct Current Stimulation (DCS)}

Another approach uses an older and more basic method to induce plasticity. Direct current stimulation (DCS) applies continuous weak current to a superficial region of the brain using two electrodes fitted on the scalp surface at carefully selected sites. Delivery of this current can have dramatic and lasting effects on ERP amplitude. The polarity of change is determined by the polarity of stimulation. ${ }^{128}$ From a theoretical perspective, given the careful research that has been conducted in animal models to determine the optimal frequency ranges of trains of discrete electrical pulses for inducing LTP and LTD, and the precise timing of pulses required to induce STDP, the effects of DCS, which is non-pulsatile, are puzzling. It has previously been demonstrated, however, that in rats DCS produces changes in the spontaneous firing rate of cortical neurons. ${ }^{129}$ Thus, plasticity induced by DCS may be the product of STDPlike interactions between DCS-induced neural activity and discrete stimulation, either in the form of electrical pulses in 
Table 1 - The potential applications of LTP/LTD-like plasticity to the treatment of neurological disorders.

\begin{tabular}{|c|c|c|c|}
\hline Disease & Underlying plasticity & Potential Method & References \\
\hline Depression & $\begin{array}{l}\text { Hyper-excitability of prefrontal } \\
\text { cortex leading to suppression of } \\
\text { activity in target sites. }\end{array}$ & $\begin{array}{l}\text { Low frequency rTMS in prefrontal cortex to induce } \\
\text { LTD-like plasticity and ameliorate hyper-excitability of } \\
\text { prefrontal cortex. }\end{array}$ & 163 \\
\hline Parkinson's disease & $\begin{array}{l}\text { Reduced nigral drive and resultant } \\
\text { loss of function in basal ganglia } \\
\text { and motor cortex. }\end{array}$ & $\begin{array}{l}\text { High frequency rTMS in motor cortex to induce LTP-like } \\
\text { plasticity and ameliorate lost basal ganglia drive; }\end{array}$ & 75 \\
\hline Schizophrenia & Hyper-excitability of sensory cortex. & $\begin{array}{l}\text { rTMS in auditory cortex to suppress auditory hallucinations } \\
\text { with LTD-like plasticity. }\end{array}$ & 164 \\
\hline Epilepsy & $\begin{array}{l}\text { Over-excitability of neural tissue in } \\
\text { epileptic focus. }\end{array}$ & $\begin{array}{l}\text { Low frequency rTMS to induce LTD-like plasticity and } \\
\text { ameliorate hyper-excitability. }\end{array}$ & 82,165 \\
\hline Stroke & Lost motor cortical tissue. & $\begin{array}{l}\text { DCS in combination with motor task or rTMS to induce } \\
\text { BDNF release and promote LTP-like plasticity in surviving } \\
\text { cortical circuitry. }\end{array}$ & 131,135 \\
\hline Chronic pain & $\begin{array}{l}\text { LTP-like plasticity in dorsal } \\
\text { horn and ACC. }\end{array}$ & $\begin{array}{l}\text { TENS to induce LTD in dorsal horn; rTMS to induce LTD in } \\
\text { ACC; Inhibition of PKM to erase LTP in ACC. }\end{array}$ & $99,103,104$ \\
\hline Amblyopia & $\begin{array}{l}\text { LTD-like plasticity in primary } \\
\text { visual cortex. }\end{array}$ & $\begin{array}{l}\text { Photic tetanus to induce LTP-like plasticity in primary visual } \\
\text { cortex; rTMS to primary visual cortex. }\end{array}$ & $108,121,122$ \\
\hline Tinnitus & $\begin{array}{l}\text { Over-representation of selected } \\
\text { frequencies in auditory cortex } \\
\text { due to LTP-like plasticity }\end{array}$ & $\begin{array}{l}\text { Vagal nerve stimulation to cause neuromodulator release } \\
\text { coupled with auditory stimulation at lost frequencies to } \\
\text { win back incorrectly allocated cortical tissue. }\end{array}$ & 147 \\
\hline
\end{tabular}

ex vivo slices, ${ }^{130}$ or, in humans, rTMS $^{131}$ or sensory stimulation resulting from a subject's participation in particular tasks. ${ }^{132,133}$ It is known that DCS causes the release of $\mathrm{BDNF}$ and that this substance modulates the induction of NMDAR-dependent LTP through the TrkB receptor. ${ }^{64}$ Moreover, a combination of DCS and lowfrequency stimulation leads to LTP in ex vivo cortical slices. ${ }^{130}$ Slices taken from mice that do not express BDNF, or in which the TrkB receptor is blocked, fail to show DCSinduced LTP. The fact that low frequencies, which would normally induce LTD, cause LTP when paired with DCS suggests that post-synaptic cells are in a permissive state for LTP as a result of DCS, just as clamping cells in a depolarized state results in low frequency-induced LTP. ${ }^{134}$

A major application of DCS has been in enhancing motor learning through stimulation of motor cortex, an approach that has great promise in facilitating recovery from stroke by promoting compensatory plasticity in spared motor cortical tissue. ${ }^{133}$ Interestingly, mice which do not express BDNF have significant deficits in motor learning. ${ }^{130} \mathrm{~A}$ common polymorphism (Val66Met) found at a frequency of $>30 \%$ in the human population is, in animal models, associated with a reduced BDNF concentrations in the synaptic cleft and with impaired motor learning, ${ }^{130}$ which suggests that a significant minority of the population may suffer from a mild impediment in motor skill acquisition. Remarkably, humans possessing this polymorphism show a reduction in motor cortical plasticity, measured using ERPs, induced by rTMS, IPAS or DCS/rTMS applied to motor cortex. ${ }^{131,135}$ Thus, there is some mechanistic understanding of the effects of DCS and why it may impact LTP/LTD. DCS is a potentially important tool for clinicians attempting to modulate synaptic plasticity to ameliorate neurological disorders, particularly in the motor system (Figure 3E).

\section{Vagal nerve stimulation}

Vagal nerve stimulation (VNS) is a related technique to TENS, but is more invasive. Direct electrical stimulation requires a minimal surgical procedure in which electrodes are wrapped around the left vagal nerve in the neck. ${ }^{136}$ Stimulation of the vagus causes, indirectly, widespread release of neuromodulatory substances such as acetylcholine, noradrenaline and dopamine through activation of the nucleus of the solitary tract. ${ }^{137}$ Release of acetylcholine from neurons originating in the nucleus basalis promotes the induction of plasticity in the cortex. ${ }^{138-141}$ Several studies have shown that coincident occupation of cholinergic receptors with stimulation of glutamatergic pathways enhances the induction of LTP/LTD. ${ }^{44,142-144}$ VNS serves as a minimally invasive, and therefore clinically viable, means of stimulating the nucleus basalis and other brainstem structures to induce release of acetylcholine and other neuromodulators. Thus it can be paired with sensory stimulation, task performance or rTMS in a combinatorial approach to maximize recuperative cortical plasticity and enhance its longevity. A recent study used this strategy to address the prevalent neurological condition of tinnitus. The manifestation of this disorder is a distracting, continuously detected tone in the absence of an external auditory stimulus. There are a multitude of causes for tinnitus, including dysfunction of the sensory apparatus itself. However, it is hypothesized to result, in part, from excessive cortical representation of a small range of sound frequencies to which the individual has previously been heavily over-exposed, ${ }^{145}$ and application of rTMS to this region has had short-lived beneficial effects. ${ }^{146}$ Induction of tinnitus in rats by repeated exposure to a loud auditory stimulus in a fixed range of frequencies leads to an overrepresentation 
of these frequencies in primary auditory cortex and a consequent under-representation of the remainder of the normal frequency range. Thus, LTD-like plasticity of synapses in the area of over-representation and LTP-like plasticity in the areas of under-representation could be used to redress the balance and, potentially, treat tinnitus. This goal has recently been accomplished in rats by pairing VNS with auditory stimuli of the appropriate frequencies to reverse physiological correlates in auditory cortex and restore detection of a full range of auditory stimuli. ${ }^{147}$ The same approach could in principle be used to treat a range of disorders that arise from cortical misrepresentation through deprivation or over-exposure.

\section{Priming}

Another important feature of experience-dependent plasticity that has been the subject of a great deal of basic research is metaplasticity. This is the phenomenon whereby the past activity of a synapse alters its susceptibility to future plasticity. We will not describe the many forms of metaplasticity that exist (see ${ }^{148}$ for review) but will briefly mention one form of metaplasticity that presents itself as an ideal candidate for augmenting the effects of non-invasive brain stimulation: priming of LTP. In a typical example of priming, a brief $5 \mathrm{hz}$ tetanus, which in itself does not alter the strength of synapses, greatly enhances the magnitude and duration of LTP induced by a standard $100 \mathrm{~Hz}$ tetanus at the same synapses, provided this is delivered within 30 minutes or so of the priming tetanus. ${ }^{149}$ It is believed that this process results from mGluR-dependent signaling, leading to an increase in intrinsic excitability of cells. Subsequent induction of LTP then becomes more effective because of the increased likelihood of action potentials and, therefore, post-synaptic depolarization for a given synaptic input. ${ }^{150}$ Priming of this sort also increases the longevity of LTP, by inducing a burst of local protein synthesis, making new proteins available for subsequent incorporation into synapses undergoing LTP. ${ }^{151}$ Priming can be achieved in the human CNS by brief application of DCS or a train of relatively low frequency rTMS to the region of interest prior to the induction of LTP-like plasticity with rTMS or motor training. ${ }^{152-155}$ These studies suggest that the exploitation of metaplasticity may prove valuable in maximizing the clinical effects of non-invasive stimulation techniques.

\section{Nootropics}

The presumed importance of LTP/LTD in mnemonic processes has prompted the launch of a number of drug discovery programs by the pharmaceutical industry aimed at improving memory function in humans and treating disorders of memory such as Alzheimer's disease and other forms of dementia. A variety of drugs, referred to as nootropics, are under development. These range from AMPA receptor modulators, known as AMPAkines, ${ }^{156}$ to drugs that increase the level of cAMP and, therefore, the activity levels of PKA and its signaling pathway. ${ }^{157}$ Substances that enhance the efficacy of neuromodulatory substances such as acetylcholine are currently the major available pharmaceutical treatments for Alzheimer's disease $^{158}$ (for reviews of nootropics see ${ }^{159,160}$ ). Note that nootropics do not themselves induce LTP, but rather modulate natural mnemonic processes. However, as with priming, nootropics could be used to enhance the effects of non-invasive LTP/LTD induction in the treatment of disease. An illustration of this combinatorial approach comes from recent work on erasing fear in sufferers of acrophobia (fear of heights) by invoking the natural process of fear extinction (see ${ }^{161}$ for review). In these studies, application of the nootropic D-cycloserine, a modulator of NMDAR function, was coupled with the use of virtual reality to mimic the experience of standing in a glass elevator, high above a vertiginous drop. ${ }^{162}$ The result was a striking loss of generalized fear of heights in individuals receiving both treatments. We can imagine extending this approach by combining the delivery of an effective nootropic with the delivery of rTMS, DCS, TENS, repetitive sensory stimulation or IPAS to enhance any of the developing therapies outlined in this review (Figure 3F).

\section{A note of caution}

In humans we can mimic the experimental protocols of frequency-dependent LTP/LTD with rTMS or TENS, and of spike-timing dependent plasticity with IPAS. However, apart from the few ex vivo experiments that have been conducted in excised human tissue, we do not have a physiological read-out in humans that allows us to be sure that we are truly observing synaptic plasticity. It is important to note that ERPs are not as easily interpretable as, for example, hippocampal field potentials. There are two reasons for this. First, the conditions that give rise to synchronous synaptic currents and hence (field EPSPs) in the hippocampus do not exist in the multilaminar neocortex; second, ERPs are recorded at a distance and not at the site of EPSP generation. Thus, the ERP represents a complex of electrical events; monosynaptic EPSPs, polysynaptic EPSPs and action potentials. As a consequence, a change in the ERP amplitude may reflect synaptic LTP/LTD, altered inhibition or increased intrinsic excitability of the underlying cell population. Other assays, such as motor threshold, are even less illuminating about mechanism. There is a burgeoning body of evidence that suggests commonalities in the molecular mechanisms of synaptic LTP/LTD in experimental preparations and noninvasive induced plasticity in humans. Nevertheless, we should exercise caution in equating non-invasively induced changes in ERP magnitude with synaptic LTP and LTD. For this reason, examples of plasticity in the human brain described in this review have been referred to as LTP-like or LTD-like. It will be of great importance to show that plasticity induced noninvasive in humans exhibits longevity, input specificity and associativity, as these are defining features of homosynaptic Hebbian LTP/LTD. A detailed, if still incomplete, mechanistic understanding of these forms of plasticity has emerged from work on animal models over the past three decades, so that a backdrop of rational drug targets and stimulation parameters is already available. Further work to clarify that rTMS, TENS, IPAS and sensory tetani do indeed induce lasting Hebbian synaptic plasticity, and, if so, to identify the synapses at which it occurs, is required if this vast knowledge base is to be effectively exploited for the non-invasive treatment of plasticity-related abnormalities in the human CNS.

\section{CONCLUSIONS}

We have described a number of methods for inducing plasticity in the human nervous system, either non-invasively or with minimally invasive surgery. TENS, rTMS, DCS, IPAS, VNS and sensory tetanic stimulation all hold significant promise as potential treatments for a wide range of neurological disorders. The debate on the physiological relevance of 
LTP and LTD to human learning will no doubt continue but, in the meantime, analogous processes may be harnessed as tools to recover lost function in the nervous system and to ameliorate the effects of pathological plasticity. These methods could, in the future, be used to rescue deficits by directly addressing the site of pathology or by inducing compensatory plasticity elsewhere. The development of stimulation strategies for the non-invasive induction of plasticity in the human CNS has been guided by basic research into LTP, LTD and STDP and, as we have seen, common molecular mechanisms are beginning to emerge in the human and animal literatures. In the future, a combination of nootropic and amnestic drugs with non-invasive stimulation techniques may emerge as the optimal therapy for plasticity-related disorders of the human CNS.

\section{ACKNOWLEDGEMENTS}

We would like to thank Dr. Steve Gomperts for reading this manuscript and providing critical comments.

\section{REFERENCES}

1. Bliss TV, Lomo T. Long-lasting potentiation of synaptic transmission in the dentate area of the anaesthetized rabbit following stimulation of the perforant path. J Physiol. 1973;232(2):331-356.

2. Hebb DO. The Organization of Behavior. New York, Wiley. 1949.

3. Ito M, Kano M. Long-lasting depression of parallel fiber-Purkinje cell transmission induced by conjunctive stimulation of parallel fibers and climbing fibers in the cerebellar cortex. Neurosci Lett. 1982;33(3):253258, doi: 10.1016/0304-3940(82)90380-9.

4. Dudek SM, Bear MF. Homosynaptic long-term depression in area CA1 of hippocampus and effects of N-methyl-D-aspartate receptor blockade. Proc Natl Acad Sci U S A. 1992;89(10):4363-4367, doi: 10.1073/pnas.89. 10.4363.

5. Martin SJ, Grimwood PD, Morris RG. Synaptic plasticity and memory: an evaluation of the hypothesis. Annu Rev Neurosci. 2000;23:649-711, doi: 10.1146/annurev.neuro.23.1.649.

6. Sanes JR, Lichtman JW. Can molecules explain long-term potentiation? Nat Neurosci. 1999;2(7):597-604, doi: 10.1038/10154.

7. Doyere V, Debiec J, Monfils MH, Schafe GE, LeDoux JE. Synapsespecific reconsolidation of distinct fear memories in the lateral amygdala. Nat Neurosci. 2007;10(4):414-416.

8. Tye KM, Stuber GD, de Ridder B, Bonci A, Janak PH. Rapid strengthening of thalamo-amygdala synapses mediates cue-reward learning. Nature. 2008;453(7199):1253-1257, doi: 10.1038/nature06963.

9. Rioult-Pedotti MS, Friedman D, Donoghue JP. Learning-induced LTP in neocortex. Science. 2000;290(5491):533-536, doi: 10.1126/science.290. 5491.533

10. Whitlock JR, Heynen AJ, Shuler MG, Bear MF. Learning induces longterm potentiation in the hippocampus. Science. 2006;313(5790):10931097, doi: 10.1126/science.1128134.

11. Gruart A, Munoz MD, Delgado-Garcia JM. Involvement of the CA3CA1 synapse in the acquisition of associative learning in behaving mice. J Neurosci. 2006;26(4):41077-1087, doi: 10.1523/JNEUROSCI.2834-05. 2006.

12. Sacchetti B, Lorenzini CA, Baldi E, Bucherelli C, Roberto M, Tassoni G, et al. Long-lasting hippocampal potentiation and contextual memory consolidation. Eur J Neurosci. 2001;13(12):2291-2298, doi: 10.1046/j. 0953-816x.2001.01609.x.

13. Cooke SF, Bear MF. Visual experience induces long-term potentiation in the primary visual cortex. J Neurosci. 2010;30(48):16304-16313, doi: 10. 1523/JNEUROSCI.4333-10.2010.

14. Neves G, Cooke SF, Bliss TV. Synaptic plasticity, memory and the hippocampus: a neural network approach to causality. Nat Rev Neurosci. 2008;9(1):65-75, doi: 10.1038/nrn2303.

15. Kemp A, Manahan-Vaughan D. Hippocampal long-term depression and long-term potentiation encode different aspects of novelty acquisition. Proc Natl Acad Sci U S A. 2004;101(21):8192-8197, doi: 10. 1073 / pnas.0402650101

16. Heynen A, Bear MF, Abraham WC. Low-frequency stimulation of the Schaffer collaterals produces homosynaptic LTD in area CA1 of the adult rat hippocampus in vivo. Soc Neurosci Abstr. 1995.

17. Bliss TV, Gardner-Medwin AR. Long-lasting potentiation of synaptic transmission in the dentate area of the unanaestetized rabbit following stimulation of the perforant path. J Physiol. 1973;232(2):357-374.
18. Abraham WC, Logan B, Greenwood JM, Dragunow M. Induction and experience-dependent consolidation of stable long-term potentiation lasting months in the hippocampus. J Neurosci. 2002;22(21):9626-9634.

19. Skrede KK, Westgaard RH. The transverse hippocampal slice: a welldefined cortical structure maintained in vitro. Brain Res. 1971;35(2):589593, doi: 10.1016/0006-8993(71)90508-7.

20. Gustafsson B, Wigstrom H, Abraham WC, Huang YY. Long-term potentiation in the hippocampus using depolarizing current pulses as the conditioning stimulus to single volley synaptic potentials. J Neurosci. 1987;7(3):774-780.

21. Markram H, Lubke J, Frotscher M, Sakmann B. Regulation of synaptic efficacy by coincidence of postsynaptic APs and EPSPs. Science. 1997;275(5297):213-215, doi: 10.1126/science.275.5297.213.

22. Bi GQ, Poo MM. Synaptic modifications in cultured hippocampal neurons: dependence on spike timing, synaptic strength, and postsynaptic cell type. J Neurosci. 1998;18(24):10464-10472.

23. Andersen P, Sundberg SH, Sveen O, Swann JW, Wigstrom H. Possible mechanisms for long-lasting potentiation of synaptic transmission in hippocampal slices from guinea-pigs. J Physiol. 1980;302:463-482.

24. Barrionuevo G, Brown TH. Associative long-term potentiation in hippocampal slices. Proc Natl Acad Sci U S A. 1983;80(23):7347-7351, doi: 10.1073 /pnas.80.23.7347.

25. Nowak L, Bregestovski P, Ascher P, Herbet A, Prochiantz A. Magnesium gates glutamate-activated channels in mouse central neurones. Nature. 1984;307(5950):462-465, doi: 10.1038/307462a0.

26. Collingridge GL, Kehl SJ, McLennan H. Excitatory amino acids in synaptic transmission in the Schaffer collateral-commissural pathway of the rat hippocampus. J Physiol. 1983;334:33-46.

27. Tsien JZ, Huerta PT, Tonegawa S. The essential role of hippocampal CA1 NMDA receptor-dependent synaptic plasticity in spatial memory. Cell. 1996;87(7):1327-1338, doi: 10.1016/S0092-8674(00)81827-9.

28. Mulkey RM, Malenka RC. Mechanisms underlying induction of homosynaptic long-term depression in area CA1 of the hippocampus. Neuron. 1992;9(5):967-975, doi: 10.1016/0896-6273(92)90248-C.

29. Lynch G, Larson J, Kelso S, Barrionuevo G, Schottler F. Intracellular injections of EGTA block induction of hippocampal long-term potentiation. Nature. 1983;305(5936):719-721, doi: 10.1038/305719a0.

30. Malenka RC, Kauer JA, Zucker RS, Nicoll RA. Postsynaptic calcium is sufficient for potentiation of hippocampal synaptic transmission. Science. 1988;242(4875):81-84, doi: 10.1126/science.2845577.

31. Cummings JA, Mulkey RM, Nicoll RA, Malenka RC. Ca2+ signaling requirements for long-term depression in the hippocampus. Neuron. 1996;16(4):825-833, doi: 10.1016/S0896-6273(00)80102-6.

32. Kemp N, Bashir ZI. Induction of LTD in the adult hippocampus by the synaptic activation of AMPA/kainate and metabotropic glutamate receptors. Neuropharmacology. 1999;38(4):495-504, doi: 10.1016/S00283908(98)00222-6.

33. Huber KM, Kayser MS, Bear MF. Role for rapid dendritic protein synthesis in hippocampal mGluR-dependent long-term depression. Science. 2000;288(5469):1254-1257, doi: 10.1126/science.288.5469.1254.

34. Lee HK, Takamiya K, Han JS, Man H, Kim CH, Rumbaugh G, et al. Phosphorylation of the AMPA receptor GluR1 subunit is required for synaptic plasticity and retention of spatial memory. Cell. 2003;112(5):631-643, doi: 10.1016/S0092-8674(03)00122-3.

35. Palmer MJ, Isaac JT, Collingridge GL. Multiple, developmentally regulated expression mechanisms of long-term potentiation at CA1 synapses. J Neurosci. 2004;24(21):4903-4911, doi: 10.1523/JNEUROSCI. 0170-04.2004.

36. Lee HK, Barbarosie M, Kameyama K, Bear MF, Huganir RL. Regulation of distinct AMPA receptor phosphorylation sites during bidirectional synaptic plasticity. Nature. 2000;405(6789):955-959, doi: 10.1038/ 35016089.

37. Lisman JE. A mechanism for memory storage insensitive to molecular turnover: a bistable autophosphorylating kinase. Proc Natl Acad Sci U S A. 1985;82(9):3055-3057, doi: 10.1073/pnas.82.9.3055.

38. Dash PK, Karl KA, Colicos MA, Prywes R, Kandel ER. cAMP response element-binding protein is activated by $\mathrm{Ca} 2+/$ calmodulin- as well as cAMP-dependent protein kinase. Proc Natl Acad Sci U S A. 1991;88(11):5061-5065, doi: 10.1073/pnas.88.11.5061.

39. Frey U, Huang YY, Kandel ER. Effects of cAMP simulate a late stage of LTP in hippocampal CA1 neurons. Science. 1993;260(5114):1661-1664, doi: 10.1126 /science.8389057.

40. Huang YY, Martin KC, Kandel ER. Both protein kinase A and mitogenactivated protein kinase are required in the amygdala for the macromolecular synthesis-dependent late phase of long-term potentiation. J Neurosci. 2000;20(17):6317-6325.

41. Huang YY, Kandel ER. D1/D5 receptor agonists induce a protein synthesis-dependent late potentiation in the CA1 region of the hippocampus. Proc Natl Acad Sci U S A. 1995;92(7):2446-2450, doi: 10. 1073/pnas.92.7.2446.

42. Johnston D, Hopkins WF, Gray R. Cellular mechanisms of noradrenergic enhancement of long-term synaptic potentiation in hippocampus. NIDA Res Monogr. 1987;78:95-107. 
43. Huang YY, Kandel ER. 5-Hydroxytryptamine induces a protein kinase $\mathrm{A} /$ mitogen-activated protein kinase-mediated and macromolecular synthesis-dependent late phase of long-term potentiation in the amygdala. J Neurosci. 2007;27(12):3111-3119, doi: 10.1523/ JNEUROSCI.3908-06.2007.

44. Welsby PJ, Rowan MJ, Anwyl R. Intracellular mechanisms underlying the nicotinic enhancement of LTP in the rat dentate gyrus. Eur J Neurosci. 2009;29(1):65-75, doi: 10.1111/j.1460-9568.2008.06562.x.

45. Frey U, Morris RG. Synaptic tagging and long-term potentiation. Nature. 1997;385(6616):533-536, doi: 10.1038/385533a0.

46. Redondo RL, Morris RG. Making memories last: the synaptic tagging and capture hypothesis. Nat Rev Neurosci. 2010;12(1):17-30, doi: 10. $1038 /$ nrn2963.

47. Ballarini F, Moncada D, Martinez MC, Alen N, Viola H. Behavioral tagging is a general mechanism of long-term memory formation. Proc Natl Acad Sci U S A. 2009;106(34):14599-14604, doi: 10.1073/pnas. 0907078106.

48. Sutton MA, Schuman EM. Dendritic protein synthesis, synaptic plasticity, and memory. Cell. 2006;127(1):49-58, doi: 10.1016/j.cell. 2006.09.014.

49. Bradshaw KD, Emptage NJ, Bliss TV. A role for dendritic protein synthesis in hippocampal late LTP. Eur J Neurosci. 2003;18(11):31503152, doi: 10.1111/j.1460-9568.2003.03054.x

50. Crick F. Memory and molecular turnover. Nature. 1984;312(5990):101, doi: 10.1038/312101a0.

51. Lengyel I, Voss K, Cammarota M, Bradshaw K, Brent V, Murphy KP, et al. Autonomous activity of CaMKII is only transiently increased following the induction of long-term potentiation in the rat hippocampus. Eur J Neurosci. 2004;20(11):3063-3072, doi: 10.1111/j.1460-9568. 2004.03748.x

52. Buard I, Coultrap SJ, Freund RK, Lee YS, Dell'Acqua ML, Silva AJ, et al. CaMKII "autonomy" is required for initiating but not for maintaining neuronal long-term information storage. J Neurosci. 2010;30(24):82148220 .

53. Sacktor TC. How does PKMzeta maintain long-term memory? Nat Rev Neurosci. 2010;12(1):9-15, doi: 10.1038/nrn2949.

54. Pastalkova E, Serrano P, Pinkhasova D, Wallace E, Fenton AA, Sacktor TC. Storage of spatial information by the maintenance mechanism of LTP. Science. 2006;313(5790):1141-1144, doi: 10.1126/science.1128657.

55. Migues PV, Hardt O, Wu DC, Gamache K, Sacktor TC, Wang YT, et al. PKMzeta maintains memories by regulating GluR2-dependent AMPA receptor trafficking. Nat Neurosci. 2010;13(5):630-634, doi: 10.1038/nn. 2531.

56. Shepherd JD, Huganir RL. The cell biology of synaptic plasticity: AMPA receptor trafficking. Annu Rev Cell Dev Biol. 2007;23:613-643, doi: 10. 1146/annurev.cellbio.23.090506.123516.

57. Enoki R, Hu YL, Hamilton D, Fine A. Expression of long-term plasticity at individual synapses in hippocampus is graded, bidirectional, and mainly presynaptic: optical quantal analysis. Neuron. 2009;62(2):242253, doi: 10.1016/j.neuron.2009.02.026

58. McGuinness L, Taylor C, Taylor RD, Yau C, Langenhan T, Hart ML, et al. Presynaptic NMDARs in the hippocampus facilitate transmitter release at theta frequency. Neuron. 2010;68(6):1109-1127, doi: 10.1016/j. neuron.2010.11.023.

59. Errington ML, Galley PT, Bliss TV. Long-term potentiation in the dentate gyrus of the anaesthetized rat is accompanied by an increase in extracellular glutamate: real-time measurements using a novel dialysis electrode. Philos Trans R Soc Lond B Biol Sci. 2003;358(1432):675-687, doi: $10.1098 /$ rstb.2002.1251.

60. Lisman J, Raghavachari S. A unified model of the presynaptic and postsynaptic changes during LTP at CA1 synapses. Sci STKE. 2006;2006(356):re11, doi: 10.1126/stke.3562006re11.

61. Nosyreva ED, Huber KM. Developmental switch in synaptic mechanisms of hippocampal metabotropic glutamate receptor-dependent longterm depression. J Neurosci. 2005;25(11):2992-3001, doi: 10.1523/ JNEUROSCI.3652-04.2005.

62. Harris KM, Fiala JC, Ostroff L. Structural changes at dendritic spine synapses during long-term potentiation. Philos Trans R Soc Lond B Biol Sci. 2003;358(1432):745-748, doi: 10.1098/rstb.2002.1254.

63. Lu B, Pang PT, Woo NH. The yin and yang of neurotrophin action. Nat Rev Neurosci. 2005;6(8):603-614, doi: 10.1038/nrn1726.

64. Figurov A, Pozzo-Miller LD, Olafsson P, Wang T, Lu B. Regulation of synaptic responses to high-frequency stimulation and LTP by neurotrophins in the hippocampus. Nature. 1996;381(6584):706-709, doi: 10. $1038 / 381706 \mathrm{a} 0$

65. Woo NH, Teng HK, Siao CJ, Chiaruttini C, Pang PT, Milner TA, et al. Activation of p75NTR by proBDNF facilitates hippocampal long-term depression. Nat Neurosci. 2005;8(8):1069-1077, doi: 10.1038/nn1510.

66. Chen WR, Lee S, Kato K, Spencer DD, Shepherd GM, Williamson A. Long-term modifications of synaptic efficacy in the human inferior and middle temporal cortex. Proc Natl Acad Sci U S A. 1996;93(15):80118015, doi: $10.1073 /$ pnas.93.15.8011.

67. Beck H, Goussakov IV, Lie A, Helmstaedter C, Elger CE. Synaptic plasticity in the human dentate gyrus. J Neurosci. 2000;20(18):7080-7086.
68. Weisskopf MG, Castillo PE, Zalutsky RA, Nicoll RA. Mediation of hippocampal mossy fiber long-term potentiation by cyclic AMP. Science. 1994:265(5180):1878-1882, doi: 10.1126/science.7916482.

69. Lie AA, Blumcke I, Beck H, Schramm J, Wiestler OD, Elger CE. Altered patterns of $\mathrm{Ca} 2+/$ calmodulin-dependent protein kinase II and calcineurin immunoreactivity in the hippocampus of patients with temporal lobe epilepsy. J Neuropathol Exp Neurol. 1998;57(11):1078-1088, doi: 10. 1097/00005072-199811000-00011.

70. Limousin P, Pollak P, Benazzouz A, Hoffmann D, Broussolle E, Perret JE, et al. Bilateral subthalamic nucleus stimulation for severe Parkinson's disease. Mov Disord. 1995;10(5):672-674, doi: 10.1002/ mds.870100523.

71. Ziemann U. TMS induced plasticity in human cortex. Rev Neurosci. $2004 ; 15(4): 253-266$

72. Anderson WS, Lenz FA. Surgery insight: Deep brain stimulation for movement disorders. Nature clinical practice. 2006;2(6):310-320, doi: 10. 1038/ncpneuro0193.

73. Goldberg JA, Boraud T, Maraton S, Haber SN, Vaadia E, Bergman H Enhanced synchrony among primary motor cortex neurons in the 1 methyl-4-phenyl-1,2,3,6-tetrahydropyridine primate model of Parkinson's disease. J Neurosci. 2002;22(11):4639-4653.

74. Drouot X, Oshino S, Jarraya B, Besret L, Kishima H, Remy P, et al. Functional recovery in a primate model of Parkinson's disease following motor cortex stimulation. Neuron. 2004;44(5):769-778, doi: 10.1016/j.neuron.2004.11.023.

75. Lefaucheur JP, Drouot X, Von Raison F, Menard-Lefaucheur I, Cesaro P, Nguyen JP. Improvement of motor performance and modulation of cortical excitability by repetitive transcranial magnetic stimulation of the motor cortex in Parkinson's disease. Clin Neurophysiol. 2004;115(11):2530-2541, doi: 10.1016/j.clinph.2004.05.025.

76. Gradinaru V, Mogri M, Thompson KR, Henderson JM, Deisseroth K Optical deconstruction of parkinsonian neural circuitry. Science. 2009:324(5925):354-359, doi: 10.1126/science.1167093.

77. Rosenberg O, Shoenfeld N, Kotler M, Dannon PN. Deep TMS in a resistant major depressive disorder: a brief report. Depress Anxiety. 2010;27(5):465-469, doi: 10.1002/da.20689.

78. Sackeim HA, Decina P, Prohovnik I, Malitz S, Resor SR. Anticonvulsan and antidepressant properties of electroconvulsive therapy: a proposed mechanism of action. Biol Psychiatry. 1983;18(11):1301-1310.

79. Kato N. Neurophysiological mechanisms of electroconvulsive therapy for depression. Neurosci Res. 2009;64(1):3-11, doi: 10.1016/j.neures. 2009.01.014

80. Fitzgerald PB, Daskalakis ZJ. The effects of repetitive transcranial magnetic stimulation in the treatment of depression. Expert Rev Med Devices. 2011;8(1):85-95, doi: 10.1586/erd.10.57.

81. Chen R, Classen J, Gerloff C, Celnik P, Wassermann EM, Hallett M, et al Depression of motor cortex excitability by low-frequency transcranial magnetic stimulation. Neurology. 1997;48(5):1398-1403.

82. Tergau F, Naumann U, Paulus W, Steinhoff BJ. Low-frequency repetitive transcranial magnetic stimulation improves intractable epilepsy. Lancet. 1999;353(9171):2209, doi: 10.1016/S0140-6736(99)01301-X

83. Fregni F, Pascual-Leone A. Technology insight: noninvasive brain stimulation in neurology-perspectives on the therapeutic potential of rTMS and tDCS. Nature clinical practice. 2007;3(7):383-393, doi: 10. $1038 /$ ncpneuro0530.

84. Kimiskidis VK. Transcranial magnetic stimulation for drug-resistan epilepsies: rationale and clinical experience. European neurology. 2010;63(4):205-210, doi: 10.1159/000282735.

85. Ahdab R, Ayache SS, Brugieres P, Goujon C, Lefaucheur JP. Comparison of "standard" and "navigated" procedures of TMS coil positioning over motor, premotor and prefrontal targets in patients with chronic pain and depression. Neurophysiol Clin. 2010;40(1):27-36

86. Julkunen P, Saisanen L, Danner N, Niskanen E, Hukkanen T, Mervaala $\mathrm{E}$, et al. Comparison of navigated and non-navigated transcranial magnetic stimulation for motor cortex mapping, motor threshold and motor evoked potentials. Neuroimage. 2009;44(3):790-795, doi: 10.1016/ j.neuroimage.2008.09.040.

87. Saisanen L, Julkunen P, Niskanen E, Danner N, Hukkanen T, Lohioja T, et al. Motor potentials evoked by navigated transcranial magnetic stimulation in healthy subjects. J Clin Neurophysiol. 2008;25(6):367-372, doi: 10.1097/WNP.0b013e31818e7944.

88. Bashir S, Edwards D, Pascual-Leone A. Neuronavigation Increases the Physiologic and Behavioral Effects of Low-Frequency rTMS of Primary Motor Cortex in Healthy Subjects. Brain Topogr. 2010.

89. Woolf CJ. Evidence for a central component of post-injury pain hypersensitivity. Nature. 1983;306(5944):686-688, doi: 10.1038/ 306686a0.

90. Randic M, Jiang MC, Cerne R. Long-term potentiation and long-term depression of primary afferent neurotransmission in the rat spinal cord J Neurosci. 1993;13(12):5228-5241.

91. Liu XG, Morton CR, Azkue JJ, Zimmermann M, Sandkuhler J. Longterm depression of C-fibre-evoked spinal field potentials by stimulation of primary afferent A delta-fibres in the adult rat. Eur J Neurosci. 1998;10(10):3069-3075, doi: 10.1046/j.1460-9568.1998.00310.x. 
92. Sandkuhler J, Liu X. Induction of long-term potentiation at spinal synapses by noxious stimulation or nerve injury. Eur J Neurosci. 1998;10(7):2476-2480, doi: 10.1046/j.1460-9568.1998.00278.x.

93. Ji RR, Kohno T, Moore KA, Woolf CJ. Central sensitization and LTP: do pain and memory share similar mechanisms? Trends Neurosci. 2003;26(12):696-705, doi: 10.1016/j.tins.2003.09.017

94. Liu XG, Sandkuhler J. Long-term potentiation of C-fiber-evoked potentials in the rat spinal dorsal horn is prevented by spinal Nmethyl-D-aspartic acid receptor blockage. Neurosci Lett. 1995;191(12):43-46, doi: 10.1016/0304-3940(95)11553-0.

95. Ikeda H, Heinke B, Ruscheweyh R, Sandkuhler J. Synaptic plasticity in spinal lamina I projection neurons that mediate hyperalgesia. Science. 2003;299(5610):1237-1240, doi: 10.1126/science.1080659.

96. Drdla R, Sandkuhler J. Long-term potentiation at C-fibre synapses by low-level presynaptic activity in vivo. Mol Pain. 2008;4:18, doi: 10.1186/ 1744-8069-4-18

97. Stubhaug A, Breivik H, Eide PK, Kreunen M, Foss A. Mapping of punctuate hyperalgesia around a surgical incision demonstrates that ketamine is a powerful suppressor of central sensitization to pain following surgery. Acta Anaesthesiol Scand. 1997;41(9):1124-1132, doi: 10.1111/j.1399-6576.1997.tb04854.x

98. Klein T, Magerl W, Hanschmann A, Althaus M, Treede RD. Antihyperalgesic and analgesic properties of the N-methyl-D-aspartate (NMDA) receptor antagonist neramexane in a human surrogate model of neurogenic hyperalgesia. Eur J Pain. 2008;12(1):17-29, doi: 10.1016/j. ejpain.2007.02.002

99. Klein T, Magerl W, Hopf HC, Sandkuhler J, Treede RD. Perceptual correlates of nociceptive long-term potentiation and long-term depression in humans. J Neurosci. 2004;24(4):964-971, doi: 10.1523/ JNEUROSCI.1222-03.2004.

100. van den Broeke EN, van Rijn CM, Biurrun Manresa JA, Andersen OK, Arendt-Nielsen L, Wilder-Smith OH. Neurophysiological correlates of nociceptive heterosynaptic long-term potentiation in humans. J Neurophysiol. 2010;103(4):2107-2113, doi: 10.1152/jn.00979.2009.

101. Wei F, Zhuo M. Potentiation of sensory responses in the anterior cingulate cortex following digit amputation in the anaesthetised rat. J Physiol. 2001;532(Pt 3):823-833, doi: 10.1111/j.1469-7793.2001.0823e.x.

102. Wu MF, Pang ZP, Zhuo M, Xu ZC. Prolonged membrane potential depolarization in cingulate pyramidal cells after digit amputation in adult rats. Mol Pain. 2005;1:23, doi: 10.1186/1744-8069-1-23.

103. De Ridder D, De Mulder G, Verstraeten E, Sunaert S, Moller A. Somatosensory cortex stimulation for deafferentation pain. Acta Neurochir Suppl. 2007;97(Pt 2):67-74, doi: 10.1007/978-3-211-33081-4_8.

104. Li XY, Ko HG, Chen T, Descalzi G, Koga $\mathrm{K}$, Wang $\mathrm{H}$, et al Alleviating neuropathic pain hypersensitivity by inhibiting PKMzeta in the anterior cingulate cortex. Science. 2010;330(6009):1400-1404, doi: 10.1126/ science. 1191792.

105. Staubli U, Scafidi J. Time-dependent reversal of long-term potentiation in area CA1 of the freely moving rat induced by theta pulse stimulation. J Neurosci. 1999;19(19):8712-8719.

106. Bliss TVP, Collingridge GL, Morris RGM. Synaptic Plasticity in the Hippocampus The Hippocampus Book 2007; eds. Andersen P, MorrisRGM, AmaralDG, O'KeefeJ, Bliss TVP (OUP (New York)): 343474.

107. Clapp WC, Zaehle T, Lutz K, Marcar VL, Kirk IJ, Hamm JP, et al. Effects of long-term potentiation in the human visual cortex: a functional magnetic resonance imaging study. Neuroreport. 2005;16(18):1977-1980, doi: 10.1097/00001756-200512190-00001.

108. Ross RM, McNair NA, Fairhall SL, Clapp WC, Hamm JP, Teyler TJ, et al. Induction of orientation-specific LTP-like changes in human visual evoked potentials by rapid sensory stimulation. Brain Res Bull. 2008;76(1-2):97-101, doi: 10.1016/j.brainresbull.2008.01.021.

109. McNair NA, Clapp WC, Hamm JP, Teyler TJ, Corballis MC, Kirk IJ. Spatial frequency-specific potentiation of human visual-evoked potentials. Neuroreport. 2006;17(7):739-741, doi: 10.1097/01.wnr.0000215775. 53732.9f.

110. Teyler TJ, Hamm JP, Clapp WC, Johnson BW, Corballis MC, Kirk IJ. Long-term potentiation of human visual evoked responses. Eur J Neurosci. 2005;21(7):2045-2050, doi: 10.1111/j.1460-9568.2005. $04007 x$.

111. Hubel DH, Wiesel TN. Ferrier lecture. Functional architecture of macaque monkey visual cortex. Proc R Soc Lond B Biol Sci. 1977;198(1130):1-59.

112. Gilbert CD, Li W, Piech V. Perceptual learning and adult cortical plasticity. J Physiol. 2009;587(Pt 12):2743-2751, doi: 10.1113/jphysiol. 2009.171488

113. Frenkel MY, Sawtell NB, Diogo AC, Yoon B, Neve RL, Bear MF. Instructive effect of visual experience in mouse visual cortex. Neuron. 2006;51(3):339-349, doi: 10.1016/j.neuron.2006.06.026.

114. Clapp WC, Eckert MJ, Teyler TJ, Abraham WC. Rapid visual stimulation induces N-methyl-D-aspartate receptor-dependent sensory long-term potentiation in the rat cortex. Neuroreport. 2006;17(5):511515, doi: 10.1097/01.wnr.0000209004.63352.10.
115. Heynen AJ, Bear MF. Long-term potentiation of thalamocortical transmission in the adult visual cortex in vivo. J Neurosci. 2001;21(24):9801-9813.

116. Webber AL, Wood J. Amblyopia: prevalence, natural history, functional effects and treatment. Clin Exp Optom. 2005;88(6):365-375, doi: 10.1111/ j.1444-0938.2005.tb05102.x.

117. Hubel DH, Wiesel TN. The period of susceptibility to the physiological effects of unilateral eye closure in kittens. J Physiol. 1970;206(2):419-436.

118. Antonini A, Stryker MP. Rapid remodeling of axonal arbors in the visual cortex. Science. 1993;260(5115):1819-1821, doi: 10.1126/science. 8511592.

119. Khibnik LA, Cho KK, Bear MF. Relative contribution of feedforward excitatory connections to expression of ocular dominance plasticity in layer 4 of visual cortex. Neuron. 2010;66(4):493-500, doi: 10.1016/j. neuron.2010.04.012

120. Huang CB, Zhou Y, Lu ZL. Broad bandwidth of perceptual learning in the visual system of adults with anisometropic amblyopia. Proc Nat Acad Sci U S A. 2008;105(10):4068-4073, doi: 10.1073/pnas.0800824105.

121. Li RW, Klein SA, Levi DM. Prolonged perceptual learning of positional acuity in adult amblyopia: perceptual template retuning dynamics. J Neurosci. 2008;28(52):14223-14229, doi: 10.1523/JNEUROSCI.4271-08. 2008.

122. Thompson B, Mansouri B, Koski L, Hess RF. Brain plasticity in the adult: modulation of function in amblyopia with rTMS. Curr Biol 2008;18(14):1067-1071, doi: 10.1016/j.cub.2008.06.052.

123. Oberman L, Edwards D, Eldaief M, Pascual-Leone A. Safety of Theta Burst Transcranial Magnetic Stimulation: A Systematic Review of the Literature. J Clin Neurophysiol. 2011

124. Classen J, Wolters A, Stefan K, Wycislo M, Sandbrink F, Schmidt A, et al. Paired associative stimulation. Suppl Clin Neurophysiol. 2004;57:563569, doi: 10.1016/S1567-424X(09)70395-2.

125. Wolters A, Schmidt A, Schramm A, Zeller D, Naumann M, Kunesch E, et al. Timing-dependent plasticity in human primary somatosensory cortex. J Physiol. 2005;565(Pt 3):1039-1052, doi: 10.1113/jphysiol.2005. 084954.

126. Wolters A, Sandbrink F, Schlottmann A, Kunesch E, Stefan K, Cohen LG, et al. A temporally asymmetric Hebbian rule governing plasticity in the human motor cortex. J Neurophysiol. 2003;89(5):2339-2345, doi: 10. $1152 /$ jn.00900.2002.

127. Weise D, Schramm A, Stefan K, Wolters A, Reiners K, Naumann M, et al. The two sides of associative plasticity in writer's cramp. Brain 2006;129(Pt 10):2709-2721, doi: 10.1093/brain/awl221.

128. Paulus W. Outlasting excitability shifts induced by direct current stimulation of the human brain. Suppl Clin Neurophysiol. 2004;57:708 714, doi: 10.1016/S1567-424X(09)70411-8.

129. Bindman LJ, Lippold OC, Redfearn JW. Long-lasting changes in the level of the electrical activity of the cerebral cortex produced bypolarizing currents. Nature. 1962;196:584-585, doi: 10.1038/196584a0.

130. Fritsch B, Reis J, Martinowich K, Schambra HM, Ji Y, Cohen LG, et al. Direct current stimulation promotes BDNF-dependent synaptic plasticity: potential implications for motor learning. Neuron. 2010;66(2):198204, doi: 10.1016/j.neuron.2010.03.035

131. Cheeran B, Talelli P, Mori F, Koch G, Suppa A, Edwards M, et al. A common polymorphism in the brain-derived neurotrophic factor gene (BDNF) modulates human cortical plasticity and the response to rTMS J Physiol. 2008;586(Pt 23):5717-5725, doi: 10.1113/jphysiol.2008.159905.

132. Kleim JA, Chan S, Pringle E, Schallert K, Procaccio V, Jimenez R, et al. BDNF val66met polymorphism is associated with modified experiencedependent plasticity in human motor cortex. Nat Neurosci. 2006;9(6):735-737, doi: 10.1038/nn1699.

133. Reis J, Schambra HM, Cohen LG, Buch ER, Fritsch B, Zarahn E, et al. Noninvasive cortical stimulation enhances motor skill acquisition over multiple days through an effect on consolidation. Proc Natl Acad Sci U S A. 2009;106(5):1590-1595, doi: 10.1073/pnas.0805413106.

134. Kirkwood A, Bear MF. Hebbian synapses in visual cortex. J Neurosci. 1994;14(3 Pt 2):1634-1645.

135. Antal A, Chaieb L, Moliadze V, Monte-Silva K, Poreisz C, Thirugnanasambandam N, et al. Brain-derived neurotrophic factor (BDNF) gene polymorphisms shape cortical plasticity in humans. Brain Stimul. 2010;3(4):230-237, doi: 10.1016/j.brs.2009.12.003.

136. Panescu D. Vagus nerve stimulation for the treatment of depression IEEE Eng Med Biol Mag. 2005;24(6):68-72, doi: 10.1109/MEMB.2005. 1549737

137. Ghanem T, Early SV. Vagal nerve stimulator implantation: an otolaryngologist's perspective. Otolaryngol Head Neck Surg. 2006;135(1):46-51, doi: 10.1016/j.otohns.2006.02.037.

138. Kang JI, Vaucher E. Cholinergic pairing with visual activation results in long-term enhancement of visual evoked potentials. PLoS One. 2009:4(6):e5995, doi: 10.1371/journal.pone.0005995.

139. Goard M, Dan Y. Basal forebrain activation enhances cortical coding of natural scenes. Nat Neurosci. 2009;12(11):1444-1449, doi: 10.1038/nn 2402. 
140. Froemke RC, Merzenich MM, Schreiner CE. A synaptic memory trace for cortical receptive field plasticity. Nature. 2007;450(7168):425-429, doi: $10.1038 /$ nature 06289 .

141. Kilgard MP, Merzenich MM. Cortical map reorganization enabled by nucleus basalis activity. Science. 1998;279(5357):1714-1718, doi: 10.1126/ science. 279.5357 .1714$.

142. Shinoe T, Matsui M, Taketo MM, Manabe T. Modulation of synaptic plasticity by physiological activation of M1 muscarinic acetylcholine receptors in the mouse hippocampus. J Neurosci. 2005;25(48):1119411200, doi: 10.1523/JNEUROSCI.2338-05.2005.

143. Hasselmo ME, Barkai E. Cholinergic modulation of activity-dependent synaptic plasticity in the piriform cortex and associative memory function in a network biophysical simulation. J Neurosci. 1995;15(10):6592-6604.

144. Brocher S, Artola A, Singer W. Agonists of cholinergic and noradrenergic receptors facilitate synergistically the induction of long-term potentiation in slices of rat visual cortex. Brain Res. 1992;573(1):27-36, doi: 10.1016/0006-8993(92)90110-U.

145. Muhlnickel W, Elbert T, Taub E, Flor H. Reorganization of auditory cortex in tinnitus. Proc Natl Acad Sci U S A. 1998;95(17):10340-10343, doi: $10.1073 /$ pnas.95.17.10340.

146. De Ridder D, De Mulder G, Menovsky T, Sunaert S, Kovacs S. Electrical stimulation of auditory and somatosensory cortices for treatment of tinnitus and pain. Prog Brain Res. 2007;166:377-388, doi: 10.1016/S00796123(07)66036-1.

147. Engineer ND, Riley JR, Seale JD, Vrana WA, Shetake JA, Sudanagunta $\mathrm{SP}$, et al. Reversing pathological neural activity using targeted plasticity. Nature. 2011.

148. Abraham WC. Metaplasticity: tuning synapses and networks for plasticity. Nat Rev Neurosci. 2008;9(5):387, doi: 10.1038/nrn2356.

149. Christie BR, Abraham WC. Priming of associative long-term depression in the dentate gyrus by theta frequency synaptic activity. Neuron. 1992;9(1):79-84, doi: 10.1016/0896-6273(92)90222-Y.

150. Cohen AS, Coussens CM, Raymond CR, Abraham WC. Long-lasting increase in cellular excitability associated with the priming of LTP induction in rat hippocampus. J Neurophysiol. 1999;82(6):3139-3148.

151. Raymond CR, Thompson VL, Tate WP, Abraham WC. Metabotropic glutamate receptors trigger homosynaptic protein synthesis to prolong long-term potentiation. J Neurosci. 2000;20(3):969-976.

152. Nitsche MA, Roth A, Kuo MF, Fischer AK, Liebetanz D, Lang N, et al. Timing-dependent modulation of associative plasticity by general network excitability in the human motor cortex. J Neurosci. 2007;27(14):3807-3812, doi: 10.1523/JNEUROSCI.5348-06.2007.

153. Carey JR, Fregni F, Pascual-Leone A. rTMS combined with motor learning training in healthy subjects. Restor Neurol Neurosci. 2006;24(3):191-199.

154. Lang N, Siebner HR, Ernst D, Nitsche MA, Paulus W, Lemon RN, et al. Preconditioning with transcranial direct current stimulation sensitizes the motor cortex to rapid-rate transcranial magnetic stimulation and controls the direction of after-effects. Biol Psychiatry. 2004;56(9):634-639, doi: 10.1016/j.biopsych.2004.07.017.

155. Butefisch CM, Khurana V, Kopylev L, Cohen LG. Enhancing encoding of a motor memory in the primary motor cortex by cortical stimulation. J Neurophysiol. 2004;91(5):2110-2116, doi: 10.1152/jn. 01038.2003.

156. Simmons DA, Rex CS, Palmer L, Pandyarajan V, Fedulov V, Gall CM, et al. Up-regulating BDNF with an ampakine rescues synaptic plasticity and memory in Huntington's disease knockin mice. Proc Natl Acad Sci U S A. 2009;106(12):4906-4911, doi: 10.1073/pnas. 0811228106

157. Barad M, Bourtchouladze R, Winder DG, Golan H, Kandel E. Rolipram, a type IV-specific phosphodiesterase inhibitor, facilitates the establishment of long-lasting long-term potentiation and improves memory. Proc Natl Acad Sci U S A. 1998;95(25):15020-15025, doi: 10.1073/pnas. 95.25.15020.

158. Birks J, Harvey RJ. Donepezil for dementia due to Alzheimer's disease. Cochrane Database Syst Rev. 2006;1:CD001190.

159. Cooke SF, Bliss TV. Long-term potentiation and cognitive drug discovery. Curr Opin Investig Drugs. 2005;6(1):25-34

160. McGaugh JL, Roozendaal B. Drug enhancement of memory consolidation: historical perspective and neurobiological implications. Psychopharmacology. 2009;202(1-3):3-14, doi: 10.1007/s00213-0081285-6.

161. Quirk GJ, Pare D, Richardson R, Herry C, Monfils MH, Schiller D, et al. Erasing fear memories with extinction training. J Neurosci. 2010;30(45):14993-14997, doi: 10.1523/JNEUROSCI.4268-10.2010.

162. Ressler KJ, Rothbaum BO, Tannenbaum L, Anderson P, Graap K, Zimand E, et al. Cognitive enhancers as adjuncts to psychotherapy: use of D-cycloserine in phobic individuals to facilitate extinction of fear. Arch Gen Psychiatry. 2004;61(11):1136-1144, doi: 10.1001/archpsyc.61. 11.1136.

163. Fitzgerald PB, Benitez J, de Castella A, Daskalakis ZI, Brown TL, Kulkarni J. A randomized, controlled trial of sequential bilateral repetitive transcranial magnetic stimulation for treatment-resistant depression. Am J Psychiatry. 2006;163(1):88-94, doi: 10.1176/appi.ajp. 163.1.88.

164. Aleman A, Sommer IE, Kahn RS. Efficacy of slow repetitive transcranial magnetic stimulation in the treatment of resistant auditory hallucinations in schizophrenia: a meta-analysis. J Clin Psychiatry. 2007;68(3):416-421, doi: 10.4088/JCP.v68n0310.

165. Rotenberg A, Bae EH, Takeoka M, Tormos JM, Schachter SC, PascualLeone A. Repetitive transcranial magnetic stimulation in the treatment of epilepsia partialis continua. Epilepsy Behav. 2009;14(1):253-257, doi: 10.1016/j.yebeh.2008.09.007. 